Seleção de características e aprendizado ativo para classificação de imagens de sensoriamento remoto

Fábio Rodrigues Jorge 

Data de Depósito:

Assinatura:

\title{
Fábio Rodrigues Jorge
}

\section{Seleção de características e aprendizado ativo para classificação de imagens de sensoriamento remoto}

\author{
Dissertação apresentada ao Instituto de Ciências \\ Matemáticas e de Computação - ICMC-USP, como \\ parte dos requisitos para obtenção do título de \\ Mestre em Ciências - Ciências de Computação e \\ Matemática Computacional. VERSÃO REVISADA \\ Área de Concentração: Ciências de Computação e \\ Matemática Computacional \\ Área de Concentração: Ciências de Computação e \\ Matemática Computacional \\ Orientador: Prof. Dr. Moacir Antonelli Ponti
}


Ficha catalográfica elaborada pela Biblioteca Prof. Achille Bassi e Seção Técnica de Informática, ICMC/USP, com os dados fornecidos pelo(a) autor(a)

Jorge, Fábio Rodrigues
J82s Seleção de características e aprendizado ativo
para classificação de imagens de sensoriamento remoto / Fábio Rodrigues Jorge; orientador Moacir Antonelli Ponti. -- São Carlos, 2015. $68 \mathrm{p}$.

Dissertação (Mestrado - Programa de Pós-Graduação em Ciências de Computação e Matemática Computacional) -- Instituto de Ciências Matemáticas e de Computação, Universidade de São Paulo, 2015.

1. seleção de características. 2. aprendizado ativo. 3. bases desbalanceadas. 4. extração de características. 5. aprendizado de máquina. I. Ponti, Moacir Antonelli, orient. II. Título. 
Data de Depósito:

Assinatura:

\title{
Fábio Rodrigues Jorge
}

\section{Feature selection with active learning for remote sensing image classification}

\author{
Master dissertation submitted to the Instituto de \\ Ciências Matemáticas e de Computação - ICMC- \\ USP, in partial fulfillment of the requirements for the \\ degree of the Master Program in Computer Science \\ and Computational Mathematics. FINAL VERSION \\ Concentration Area: Computer Science and \\ Computational Mathematics \\ Advisor: Prof. Dr. Moacir Antonelli Ponti
}



Em aplicações de sensoriamento remoto, há diversos problemas nos quais há conhecimento predominante sobre uma categoria ou classe alvo, e pouco conhecimento sobre as demais categorias. Nesses casos, o treinamento de um classificador é prejudicado pelo desbalanceamento de classes. Assim, o estudo de características visuais para se definir o melhor subespaço de características pode ser uma alternativa viável para melhorar o desempenho dos classificadores. O uso de abordagens baseadas em detecção de anomalias também pode auxiliar por meio da modelagem da classe normal (comumente majoritária) enquanto todas as outras classes são consideradas como anomalias. Este estudo apresentou uma base de imagens de sensoriamento remoto, cuja aplicação é identificar entre regiões de cobertura vegetal e regiões de não cobertura vegetal. Para solucionar o problema de desbalanceamento entre as classes, foram realizados estudos das características visuais a fim de definir qual o conjunto de atributos que melhor representa os dados. Também foi proposta a criação de um pipeline para se tratar bases desbalanceadas de cobertura vegetal. Este pipeline fez uso de técnicas de seleção de características e aprendizado ativo. A análise de características apresentou que o subespaço usando o extrator BIC com o índice de vegetação ExG foi o que melhor distinguiu os dados. Além disso, a técnica de ordenação proposta mostrou bom desempenho com poucas dimensões. $\mathrm{O}$ aprendizado ativo também ajudou na criação de um modelo melhor, com resultados caomparáveis com as melhores características visuais.

Palavras Chave: Seleção de características, Aprendizado Ativo, Bases desbalanceadas, Extração de características, Aprendizado de máquina 
In remote sensing applications, there are several problems in which there is predominant knowledge about a target category or class, and little knowledge of the other categories. In such cases, the training of a classifier is hampered by the class imbalance. Thus, the study of visual characteristics to determine the best subspace characteristics may be a feasible alternative to improve the performance of classifiers. The use of anomaly detection-based approaches can also help through the normal class modeling (usually the major class) while considering all other classes as anomalies. This study presents a remote sensing image dataset, whose application is to classify regions of the image into vegetation coverage (related to plantation) and non-vegetation coverage. To solve the class imbalance problem, studies were conducted using several visual characteristics in order to define the set of attributes that best represent the data. A pipeline that deals with the vegetation classification problem and its class imbalance issues is also proposed. This pipeline made use of feature selection techniques and active learning. The visual features analysis showed that a subspace using the BIC extractor with EXG vegetation index was the best to distinguished the data. Also, and the proposed sorting-based feature selection achieved good results with a low dimensional subspaces. Furthermore, the active learning helped creating a better model, with results comparable with the best visual features.

Keywords: Feature selection, Active learning, Imbalanced dataset, Feature extraction, Machine learning 


\section{Agradecimentos}

Agradeço primeiramente minha mãe Irene, por tudo, e principalmente por sempre me incentivar a estudar. Te amo mãe.

Agradeço também a minha irmã pentelha, Carina. Te amo tatinha.

Agradeço minha namorada Daniele, que suportou todo esse tempo longe de mim. Te amo.

Agradeço aos amigos do VICG pelo ambiente gostoso e cheio de café: Danilo, Tácito, Gladys, Vinicius, Renato, Fabinho, Mineiro, Karina, Welinton, Samuel, Chicão, Lucas.

Agradeço aos amigos do eterno SemDisquete: Fernando, Honda, Davi, Helder, Giu e Richard. Obrigado pelos DANs da vida.

Agradeço aos amigos e parceiros de pesquisa: Gabriel, Gabriela e Tiago. Obrigado pelas dicas, experiências e jogatinas que tivemos.

Agradeço aos amigos Carlos, Jorge e Sonia pela amizade, companheirismo e risadas. Bons tempos de cinelab!

Agradeço aos meus antigos professores da UNIVEM: Elvis, Fabio Dacêncio, Leonardo, Sabatine e Rodolfo. Obrigado pelas dicas.

Agradeço também aos amigos Alexandre, Aubrey, Carol, Eduardo, Jefferson e Suellen. As conversas com vocês sempre me ajudaram nessa empreitada. Obrigado.

Agradeço ao meu orientador: Moacir. Obrigado por todas as dicas e experiências. Vejo em você o exemplo de profissional que eu quero ser. Obrigado por tudo. 
1 Introdução 1

1.1 Contexto e Motivação . . . . . . . . . . . . . . . . . . . 2

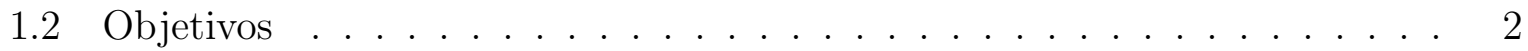

1.3 Hipótese . . . . . . . . . . . . . . . . . . . . . . . . . . 3

1.4 Contribuições . . . . . . . . . . . . . . . . . . . . . . 3

1.5 Organização do Trabalho . . . . . . . . . . . . . . . . . . . 3

2 Características Visuais em Imagens 5

2.1 Considerações Iniciais . . . . . . . . . . . . . . . . . . . . . . . . . 5

2.2 Extração de Características Visuais de Imagens . . . . . . . . . . . . . 5

2.2.1 Dimensão Intrínseca e Características Ideais . . . . . . . . . . . 6

2.2 .2 Extratores de cor . . . . . . . . . . . . . . . . 7

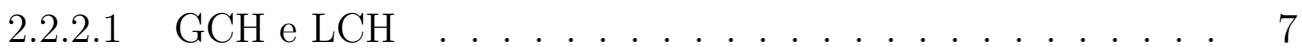

2.2.2.2 Border/Interior Classification . . . . . . . . . . . 8

2.2.3 Extratores de textura . . . . . . . . . . . . . . 8

2.2.4 Extrator baseado em Histograma de Gradientes Orientados . . . . . 10

2.3 Índices de Vegetação . . . . . . . . . . . . . . . . . . . . . . . . . . . . . . . . . . . . . . . . . . . . . . .

$2.3 .1 \mathrm{ExG} \ldots \ldots \ldots \ldots \ldots \ldots \ldots$

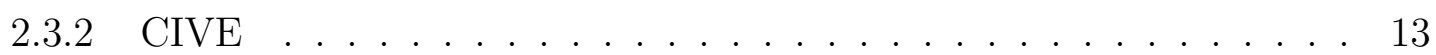

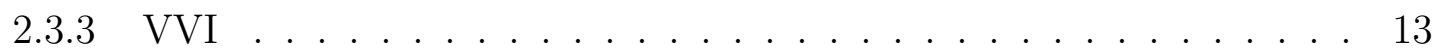

2.4 Considerações Finais . . . . . . . . . . . . . . . . . . . . . . . . . 13

3 Aprendizado de Máquina $\quad 15$

3.1 Considerações Iniciais . . . . . . . . . . . . . . . . . . . . . . . . . . . . . . . . . . . . . . . . . .

3.2 Bases Desbalanceadas . . . . . . . . . . . . . . . . . . 15

3.3 Aprendizado de Máquina . . . . . . . . . . . . . . . . . . . . . 16

3.3.1 Aprendizado Supervisionado . . . . . . . . . . . . . . . . 17

3.3.1.1 Support Vector Machine (SVM) . . . . . . . . . . . . 17

3.3.1.2 Optimum Path Forest $(\mathrm{OPF})$. . . . . . . . . . . 20

3.3.2 Detectores de Anomalias . . . . . . . . . . . . . . . . 21

3.3.2.1 Gaussiana Multivariada (GM) . . . . . . . . . . . . . 21

3.4 Aprendizado Ativo . . . . . . . . . . . . . . . . . . . 22 
3.4 .1 Heurísticas . . . . . . . . . . . . . . . . . . . . . . 24

3.4 Aplicações . . . . . . . . . . . . . . . . . . 24

3.5 Seleção e Transformação de Características . . . . . . . . . . . . . . . . . . 25

3.5.1 Transformação de Características . . . . . . . . . . . . . 26

3.5.2 Seleção de Características . . . . . . . . . . . . . . . 26

3.6 Métricas de Avaliação em Bases Desbalanceadas . . . . . . . . . . . . . . . 27

3.6.1 Acurácia Balanceada . . . . . . . . . . . . . . . . . 27

3.7 Considerações Finais . . . . . . . . . . . . . . . . . . . . . 28

4 Metodologia 29

4.1 Considerações Iniciais . . . . . . . . . . . . . . . . . . . . . . . . . . 29

4.2 Base de imagens de cobertura vegetal . . . . . . . . . . . . . . . . . 29

4.2.1 Aquisição da base de dados . . . . . . . . . . . . . . . . . . . . . . 30

4.2.2 Extração de Características da base . . . . . . . . . . . . . . . . 32

4.2.3 Análise das características da base de dados . . . . . . . . . . . . . 33

4.3 Seleção de características em bases desbalanceadas . . . . . . . . . . . . . . . 35

4.3.1 Seleção por ordenação . . . . . . . . . . . . . . . 36

4.3.2 Seleção de características com aprendizado ativo . . . . . . . . . . . 40

4.4 Análise com PCA . . . . . . . . . . . . . . . . . . . . . . . 42

4.5 Considerações Finais . . . . . . . . . . . . . . . . . . . . 43

5 Resultados e Discussões $\quad 45$

5.1 Considerações Iniciais . . . . . . . . . . . . . . . . . . . . . . . . . . . . . . . . . . . . 45

5.2 Análise das características da base de dados . . . . . . . . . . . . . . 45

5.3 Seleção de características por ordenação . . . . . . . . . . . . . . . 47

5.3 .1 Seleção por ordenação . . . . . . . . . . . . . . . . . . . 47

5.3 .2 Pipeline $1 \ldots \ldots \ldots \ldots \ldots$. . . . . . . . . . . . . . . . . . . . . . 51

5.3 .3 Pipeline 2 - Adicionando Aprendizado Ativo . . . . . . . . . . . . . . 52

5.3 .4 Análise com PCA . . . . . . . . . . . . . . . . . 54

5.4 Considerações Finais . . . . . . . . . . . . . . . . . . . . . 58

6 Conclusões $\quad 59$

6.1 Conclusões . . . . . . . . . . . . . . . . . . . . . . . . . 59

6.2 Limitações . . . . . . . . . . . . . . . . . . . . . . . . . 60

6.3 Trabalhos Futuros . . . . . . . . . . . . . . . . . 60

6.4 Agradecimentos . . . . . . . . . . . . . . . . . . . 61

$\begin{array}{ll}\text { Referências Bibliográficas } & 63\end{array}$ 
2.1 A figura (a) é uma imagem de teste. A figura (b) representa os gradientes descendentes com suas orientações e magnitudes. . . . . . . . . . . . . . . . 11

2.2 A imagem (a) é a imagem original enquanto (b), (c) e (d) representam as imagens resultantes das técnicas ExG, CIVE e VVI $(w=1)$ respectivamente. 12

3.1 Exemplo de conjunto de dados linearmente separáveis com os hiperplanos separador e canônicos. Adaptado de (Faceli et al., 2011). . . . . . . . . . 19

3.2 Ciclo do aprendizado ativo pool-based (Settles, 2009) . . . . . . . . . . 23

3.3 Imagens de satélites. Detecção de piscinas no lado esquerdo e de táxis amarelos no lado direito (Bietti, 2012) . . . . . . . . . . . . . 25

4.1 Helikite de modelo Skyhook (Verhoeven et al., 2009). . . . . . . . . . . . . 30

4.2 Exemplos de imagens obtidas das duas diferentes culturas. As imagens da coluna (a) e (b) são imagens da cultura 1; (c) e (d) são da cultura 2. As imagens (a) e (c) representam as imagens RGB, e as imagens (b) e (d) representam o ground truth em que as regiões iluminadas representam os rótulos positivos (cobertura vegetal) e as regiões escuras os rótulos negativos. 31

4.3 Fluxo da extração de características . . . . . . . . . . . . . . . . . . 33

4.4 Formação dos vetores de característica do primeiro experimento . . . . . . 34

4.5 Formação dos vetores de características do segundo experimento . . . . . . . 34

4.6 Pipeline proposto para automatizar o processo de extração e seleção de características . . . . . . . . . . . . . . . . . 35

4.7 Exemplo hipotético. $\operatorname{Var} 1$ é a variância da dimensão 1 e $\operatorname{Var} 2$ é a variância da dimensão 2. A hipótese desse método é que, quanto menor a variância da dimensão, menor são as chances dela de separar os exemplos de classes distintas. . . . . . . . . . . . . . . . . . . 37

4.8 Exemplo hipotético. As imagens (a) e (b) exemplificam duas distribuições gaussianas, de classes vermelha e azul, onde em ambas as imagens as médias são iguais porém os desvios padrões são diferentes. Na imagem (a) o desvio padrão é de 1 enquanto na imagem (b) o desvio padrão é de 0.6. A hipótese é que quanto maior a variância em cada classe, maiores são as chances de sobreposição dos dados das classes distintas. . . . . . . . . . . . . . . . 38 
4.9 Exemplo hipotético. As imagens (a) e (b) exemplificam duas distribuições gaussianas, de classes vermelha e azul, onde em ambas as imagens os desvios padrões são iguais porém as médias se alteram. Na imagem (a) a média é de $(-5,0)$ e $(5,0)$ enquanto na imagem (b) a média é de $(-1,0)$ e $(1,0)$. É observado que quanto maior o desvio padrão, maiores são as chances de sobreposição entre as classes. . . . . . . . . . . . . . . . . . . . . 39

4.10 Pipeline 2: Adicionada a etapa de aprendizado ativo em relação ao primeiro pipeline. . . . . . . . . . . . . . . . . . 42

5.1 Exemplo de imagem da base de dados que possui classes rotuladas erradas. A região circulada mostra vegetações similares a da plantação. As regiões claras são de cobertura vegetal e as escuras da classe oposta. . . . . . . . . 47

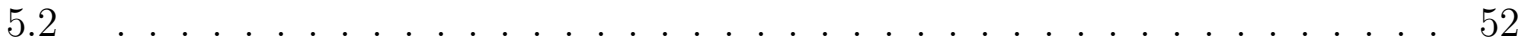

5.3 Imagem apresentando a variância das dimensões do PCA. São apresentadas as 10 primeiras dimensões de 328. . . . . . . . . . . . . . . . 55

5.4 Projeção dos dois primeiros componentes principais do PCA . . . . . . . . 56

5.5 Projeção das duas primeiras dimensões fornecidas pela ordenação da diferença das médias como apresentado na Tabela $5.2 \ldots$. . . . . . . . . . . . 57 


\section{Lista de Tabelas}

5.1 Acurácia média e desvio padrão dos experimentos . . . . . . . . . . . 46

5.2 Dimensões ordenadas de acordo com cada técnica de ordenação sendo mais importante a característica mais alta no ranking. São apresentadas as 17 primeiras dimensões de cada técnica. A técnica 1 é a ordenação pela maior variância; a técnica 2 é a ordenação pela menor soma das variâncias de cada classe; a técnica 3 é a ordenação pela maior diferença das médias das classes. . . . . . . . . . . . . . . . . . . . . 48 48

5.3 Resultado dos testes usando o Kernel Polinomial e o algoritmo SVM. . . 49

5.4 Resultado dos testes usando o Kernel Radial e o algoritmo SVM. . . . . . 50

5.5 Resultado dos testes usando o algoritmo GM. . . . . . . . . . . . . . . 50

5.6 Resultado dos testes dos algoritmos SVM e GM com as dimensões calculadas com o conjunto de treinamento, de acordo com o pipeline proposto.

5.7 Resultado dos testes de acordo com o Pipeline 2. Foi utilizado o algoritmo SVM com kernel Radial com e sem aprendizado ativo. . . . . . . . . . . . 53

5.8 Quantidade de exemplos selecionados pela heurística de aprendizado ativo em cada um dos folds. No fold 40, os exemplos 1 e 15 foram ignorados por não possuírem exemplos da classe negativa. . . . . . . . . . . . . . 53

5.9 Resultado dos testes de acordo com o Pipeline 2. Foi utilizado o algoritmo SVM com kernel Radial com e sem aprendizado ativo. . . . . . . . . . . . . 58 


$\begin{array}{ll}\text { AP } & \text { Agricultura de Precisão } \\ \text { AM } & \text { Aprendizado de Máquina } \\ \text { AA } & \text { Aprendizado Ativo } \\ \text { SVM } & \text { Support Vector Machine } \\ \text { RNA } & \text { Redes Neurais Artificias } \\ \text { OPF } & \text { Optimum-Path Forest } \\ \text { IFT } & \text { Image Foresting Transform } \\ \text { LPD } & \text { Low Probability Detection } \\ \text { SVDD } & \text { Support Vector Data Description } \\ \text { CH-AD } & \text { Conex Hull Anomaly Detector } \\ \text { VP } & \text { Verdadeiro Positivo } \\ \text { VN } & \text { Verdadeiro Negativo } \\ \text { FP } & \text { Falso Positivo } \\ \text { FN } & \text { Falso Negativo } \\ \text { TFN } & \text { Taxa de Falsos Negativos } \\ \text { TFP } & \text { Taxa de Falsos Positivos } \\ \text { TVP } & \text { Taxa de Verdadeiros Positivos } \\ \text { MLE } & \text { Maximum Likelihood Estimation } \\ \text { GCH } & \text { Global Color Histogram } \\ \text { LCH } & \text { Local Color Histogram } \\ \text { BIC } & \text { Border/Interior Classification } \\ \text { CCV } & \text { Color Coherence Vectors } \\ \text { HOG } & \text { Histograms of Oriented Gradients } \\ \text { ExG } & \text { Excess Green } \\ \text { ExR } & \text { Excess Red } \\ \text { CIVE } & \text { Color Index of Vegetation Extraction } \\ \text { VVI } & \text { Visible Vegetation Index } \\ \text { MS } & \text { Margin Sample } \\ \text { VANTS } & \text { Veículo Aéreo Não Tripulado } \\ & \end{array}$




\begin{tabular}{l|l}
\hline & Capítulo \\
\hline & 7 \\
\hline & 7 \\
\hline
\end{tabular}

\section{Introdução}

A agricultura passou por grandes avanços nos últimos 20 anos. Diversas tecnologias e sistemas que antes existiam apenas nas indústrias passaram a ser usadas também na agricultura. Tecnologias como a engenharia genética de sementes ou a automação das produções. O processo de levar a tecnologia para o campo, a fim de diminuir custos e melhorar o desempenho da produção, é chamada de Agricultura de Precisão (AP) (Zhang et al., 2002).

O sensoriamento remoto de imagens é uma das ferramentas amplamente usadas na AP. As imagens podem ser obtidas de diversas altitudes e com diversos mecanismos diferentes. Variam de imagens RGB ou infra-vermelho próximo até imagens hiperespectrais com dezenas de canais. As imagens obtidas são usadas para diferentes fins na AP, tais como: tomada de decisão; aplicação de inseticidas (Zhang et al., 2002); fertilização de precisão; detecção de anomalias (Carter et al., 2000).

Usar esse tipo de imagens possui um custo elevado. Muitas vezes as imagens precisam ser compradas de empresas especializadas, e isso encarece e desencoraja o investimento na AP. Há diversas alternativas ao imageamento por satélite para a obtenção de imagens e que apresentam menor custo de aquisição, dentre os quais se destacam aviões, balões e pipas, todos para captura em baixa altitude. Uma alternativa comercialmente viável é um híbrido de pipa com dirigível, que é capaz de sobrevoar as plantações, e por meio de um sensor CCD de 10MP, obter imagens aéreas da plantação (Verhoeven et al., 2009). 
Para este trabalho, foi proposta uma base de dados obtida utilizando um mecanismo similar ao citado acima. A base de imagens foi obtida a fim de identificar regiões com cobertura vegetal e regiões com ausência de cobertura vegetal, em duas plantações distintas de feijão. Pela natureza do problema, é possível abordá-lo como um problema de detecção de anomalias. A base de dados possui muitos exemplos da classe de cobertura vegetal, também chamada de classe normal, e poucos exemplos da classe anômala, também chamada de negativa, e que é composta por diversas distribuições, visto que as anomalias originam de diversas fontes como: solo, plantas daninhas, vegetação rasteira, objetos, pessoas, entre outros. Essa base também pode ser considerada uma base desbalanceada dada a quantidade de exemplos em cada classe.

Bases desbalanceadas exigem cuidados especiais que vão desde da extração de características e normalização dos dados, até o processo de escolha do classificador e a forma de avaliar o desempenho dos mesmos.

\subsection{Contexto e Motivação}

Definir as melhores características a serem extraídas de uma base de imagens não é uma tarefa fácil. As características extraídas devem separar os dados de diferentes classes, e aproximarem os dados pertencentes á mesma classe. A causa, na maioria das vezes, do baixo desempenho em sistemas de visão computacional, é justamente não conseguir extrair tais características discriminativas.

A base de imagem de sensoriamento remoto apresentada neste trabalho possui diversas dificuldades que atrapalham o processo de classificação. Além da dificuldade de se definir quais as características que melhor descrevem a base, essa base possui um certo grau de desbalanceamento. O desbalanceamento entre classes está presente em diversas aplicações de sensoriamento remoto (Alajlan et al., 2014) (Carter et al., 2008).

\subsection{Objetivos}

Este trabalho possui dois objetivos, em que ambos fazem uso da base proposta. A base de imagens é de sensoriamento remoto de cobertura vegetal, e possui duas classes: a de cobertura vegetal (positiva) e a negativa.

O primeiro objetivo envolve um estudo de características visuais da base de dados a fim de definir quais as melhores características representam a base. O estudo fará o uso de diversos índices de vegetação combinados com diferentes extratores de características. 
Acredita-se que com essa abordagem é possível extrair o máximo de informações das imagens. Assim é possível definir qual a melhor combinação de índices de vegetação e de extratores de características.

O segundo objetivo propõe a criação de um pipeline para obter as dimensões intrínsecas existentes na base de dados de forma automática, bem como um subespaço que melhor represente os dados. Esse pipeline deverá ser responsável por extrair as características, selecionar as características intrínsecas, e então treinar um classificador. É proposto também o uso de aprendizado ativo a fim de melhorar o desempenho da classificação.

\subsection{Hipótese}

O uso de um método integrado de aprendizado ativo e seleção de características permite aumentar a acurácia balanceada num problema de classificação de cobertura vegetal em imagens de sensoriamento remoto com classes desbalanceadas. Ao mesmo tempo, diminui a dimensão do espaço de características e a quantidade de exemplos necessários para treinar o classificador.

\subsection{Contribuições}

Considerando a aplicação em um conjunto de imagens de cultivo de feijão para classificação de cobertura vegetal, as principais contribuições foram:

- Análise do espaço de características extraídas das imagens;

- Um método de seleção de características baseado em ordenação e dimensão intrínseca;

- Um processo de aprendizado ativo que seleciona ao mesmo tempo exemplos a serem rotulados e as melhores características que representam o modelo atual.

\subsection{Organização do Trabalho}

O restante desta monografia está estruturada da seguinte maneira:

- No Capítulo 2 serão abordados os conceitos envolvendo o estudo das características. Também serão apresentados os índices de vegetação e os extratores de características usados. 
- No Capítulo 3 serão abordados os conceitos de aprendizado de máquina, detecção de anomalia e aprendizado ativo. Também são apresentadas as técnicas de redução de dimensionalidades. Nesse capítulo também são discutidas e apresentadas formas de avaliação de bases desbalanceadas.

- No Capítulo 4 será apresentada a proposta do projeto. Nesse capítulo é apresentada a base de imagens de cobertura vegetal usada no projeto. Também é apresentado o pipeline proposto e uma descrição dos testes computacionais.

- No Capítulo 5 serão apresentados os resultados e as discussões. Nesse capítulo são apresentados os comparativos dos desempenhos dos classificadores.

- No Capítulo 6 serão apresentadas as conclusões. 


=

\section{Características Visuais em Imagens}

\subsection{Considerações Iniciais}

É apresentado neste capítulo o conjunto de métodos para extrair as características visuais da base de dados. Primeiramente são apresentados os diferentes tipos de extração de características e suas técnicas. Em seguida são descritos os índices de vegetação usados para realçar a vegetação contida nas imagens.

\subsection{Extração de Características Visuais de Imagens}

A extração de características é uma etapa fundamental para o bom funcionamento dos sistemas de visão computacional. É essencial definir as características que melhor discriminem a base de imagens com relação às classes existentes. As características escolhidas devem procurar destacar as diferenças entre imagens de classes diferentes e capturar as semelhanças de imagens de mesma classe. Existem vários tipos de características visuais que podem ser capturadas em imagens como cor, textura, forma e orientação. Sistemas de visão computacional como por exemplo os CBIRs, possuem o desempenho diretamente relacionado às técnicas de extração de características utilizadas (Demir e Bruzzone, 2015).

O método de extração de característica produz o vetor de características, que é um vetor $d$ dimensional contendo informações obtidas da imagem. Dependendo da técnica 
usada, a quantidade de dimensões do vetor pode se alterar. Nas técnicas que usam os extratores de cor, por exemplo, o tamanho do vetor depende da quantização das imagens.

\subsubsection{Dimensão Intrínseca e Características Ideais}

A escolha de qual característica extrair para determinada base não é uma tarefa fácil. Cada domínio exige a escolha de características diferentes, e não existe uma regra geral para definir qual técnica utilizar. O ideal é capturar as características que melhor distinguem e separem os dados das diferentes classes envolvidas.

Uma alternativa para essa dificuldade é extrair diversas características distintas e concatenar todas elas em um único vetor de características. O problema dessa alternativa é a quantidade de dimensões que o vetor de característica poderia ter. Um vetor com muitas dimensões, além de aumentar o custo do processamento, não é bem aceito por algoritmos de aprendizado de máquina devido a chamada "maldição da dimensionalidade" (Domingos, 2012). Esse termo foi usado primeiramente por Bellman e Bittner (1962) se referindo ao fato de que, muitos algoritmos de aprendizado de máquina que funcionam bem com poucas dimensões, mas com grande número de dimensões, tornam-se inefetivos. Esse problema será abordado com maiores detalhes no Capítulo 3.

Outra alternativa para definir qual o melhor extrator para determinada base de dados é utilizar algoritmos de aprendizado de máquina. Essa abordagem propõe a extração de diversas características distintas da base de imagens, e após isso, usar um algoritmo de classificação para avaliar qual a melhor técnica de extração. A técnica de extração que produzir o melhor resultado do classificador é eleita a melhor técnica para a base de imagens. Essa alternativa possui algumas variáveis que podem influenciar na decisão, como a escolha do algoritmo de classificação e da medida de avaliação.

Quando se tem tem uma grande quantidade de dados disponível, também é possível aplicar técnicas de Deep Learning para assim aprender as características com base nos dados (Bengio et al., 2014).

Como foi mencionado, não existe uma fórmula ou um modo automático de extrair as melhores características da base de imagens para uma aplicação específica. O que pode ser feito nesses casos é um estudo visual da base de imagens por especialistas, a fim de encontrar quais são as características que melhor separam as classes.

Existem os chamados estimadores de dimensões intrínsecas que, dada uma base de dados de $d$ dimensões, essas técnicas estimam o número de dimensões intrínsecas existentes na base. Por exemplo, se uma base possui 1000 dimensões e o estimador de dimensões intrínsecas retornou o valor 10, isso indica que apenas 10 das 1000 dimensões são necessárias para separar os dados entre as classes. Vale ressaltar que o estimador apenas indica 
a quantidade de dimensões intrínsecas, e não qual o é o subespaço com as dimensões que melhor representam os dados.

Um estimador de dimensões intrínsecas foi proposto por Levina e Bickel (2004). A técnica proposta se chama MLE (do inglês Maximum Likelihood Estimation), e ela estima a quantidade de dimensões intrínsecas usando o princípio da máxima verossimilhança às distâncias entre vizinhos próximos. Essa técnica possui um parâmetro $K$, que indica a quantidade de vizinhos mais próximos que serão usados para análise da base. No estudo comparativo dessa técnica foi sugerido o uso do parâmetro $K=10$ para o número de vizinhos (Levina e Bickel, 2004).

\subsubsection{Extratores de cor}

Ao se trabalhar com imagens naturais como as de sensoriamento remoto, a cor é uma das características mais discriminativas. Uma das maneiras mais simples de se capturar a informação de cor em imagens é a utilização dos histogramas. Existem varias técnicas que fazem o uso do histograma de cor como: GCH (do inglês Global Color Histogram), LCH (do inglês Local Color Histogram) e BIC (do inglês Border/Interior Classification) (Swain e Ballard, 1991) (Lu et al., 1994) (Stehling et al., 2002).

Conforme estudo porposto por Ponti et al. (2015), o extrator BIC se demonstrou eficaz no processamento de imagens naturais.

\subsubsection{GCH e LCH}

A abordagem mais simples para se capturar a informação de cor é usando o GCH (Swain e Ballard, 1991). O histograma do GCH é um vetor ordenado dos valores de intensidade da imagem, e cada posição desse vetor registra a distribuição de probabilidade que um pixel pode ser de determinada cor. A quantização da imagem está diretamente relacionada ao tamanho do vetor. Caso a imagem possua 256 níveis de intensidades, o vetor gerado pelo GCH também possuirá 256 dimensões. Muitas vezes, um vetor com 256 não é desejável já que pode ser custoso seu processamento, o que se faz necessário quantizar a imagem para outros valores como 64, 32 ou até 16 níveis (Almeida et al., 2008).

Após gerar o histograma é ideal realizar uma normalização em seus valores para que a soma de todas as posições seja 1. O LCH é outro histograma que registra a distribuição de cores da imagem (Lu et al., 1994). A diferença é que o GCH captura a distribuição global da imagem, enquanto o LCH procura capturar a distribuições de regiões locais da imagem. O LCH divide as imagem em células de tamanho iguais e então extrai a distribuição de cor de cada célula (Almeida et al., 2008). 
Os histogramas de cor GCH e LCH podem ser sensíveis as íluminação. O LCH também é sensível à mudanças de ponto de vista e rotação, tornando-o pouco interessante para aplicações de sensoriamento remoto.

\subsubsection{Border/Interior Classification}

O BIC também é um extrator de cor, que se baseia na ideia de registrar em histogramas a distribuição global de probabilidade das cores na imagem. Primeiramente, esse extrator quantiza os canais da imagem colorida em 4 cores por canal, gerando então $4 \times 4 \times 4=64$ níveis. Após esse processo, os pixels são então classificados em pertencentes a borda ou ao interior. Um pixel é classificado como interior caso os 4-vizinhos possuem os mesmos valores de intensidade com referência ao pixel central. Caso um ou mais dos 4-vizinhos possua um valor diferente do pixel central ou o pixel central está localizado na região de borda da imagem, então esse pixel é classificado como pixel de borda (Stehling et al., 2002).

Após classificar os pixels, são computados dois histogramas de 64 posições, um referente aos pixels de borda e o outro referente aos pixels de interior. Os dois histogramas são então concatenados para se formar um único vetor de 128 dimensões.

\subsubsection{Extratores de textura}

Texturas para os humanos, é o aspecto que a superfície de um objeto possui, ou seja, se a superfície transmite a percepção de ser áspera, rugosa, lisa, macia, ondulada, etc. Em processamento de imagem, a textura nos fornece informações da disposição das cores e níveis de intensidade dos pixels.

Usando uma abordagem estatística é possível extrair informações da textura. Nessa abordagem é usada a matriz de co-ocorrência $P_{i, j}$ de tamanho $L \times L$ para capturar a distribuição e relação das intensidades dos pixels, onde $L$ representa a quantidade de intensidades. Essa matriz registra as ocorrência dos pixels dada uma relação espacial $Q=(x, y)$ no qual $x$ é o deslocamento no eixo $x$, e $y$ o deslocamento no eixo $y$ com relação ao pixel de referência. As linhas dessa matriz são os pixels de referência e as colunas são os pixels alvos. A quantidade de linhas e colunas varia de acordo com a quantidade de níveis de intensidade que as imagens foram quantizadas (Haralick et al., 1973).

Após obter essa matriz, são então calculados os descritores de Haralick, propostos por Haralick et al. (1973) e calculados a partir de matrizes de co-ocorrência. A seguir são apresentados os seis descritores de Haralick (Pham et al., 2007) usados nesse trabalho, em 
que $\mu_{r}, \mu_{c}, \sigma_{r}^{2}$ e $\sigma_{c}^{2}$ são as médias e variâncias das linhas e colunas. As médias e variâncias são apresentadas nas Equações 2.1 e 2.2.

$$
\begin{gathered}
\mu_{r}=\sum_{i=1}^{L} \sum_{j=1}^{L} i P_{i, j}, \quad \mu_{c}=\sum_{i=1}^{L} \sum_{j=1}^{L} j P_{i, j} \\
\sigma_{r}^{2}=\sum_{i=1}^{L} \sum_{j=1}^{L}\left(i-\mu_{r}\right) P_{i, j}, \quad \sigma_{c}^{2}=\sum_{i=1}^{L} \sum_{j=1}^{L}\left(j-\mu_{c}\right) P_{i, j}
\end{gathered}
$$

A probabilidade máxima determina o par de pixels mais predominantes na imagem, ou seja, é o impulso mais forte existente na matriz. A probabilidade máxima é apresentada na Equação 2.3.

$$
\max _{i, j} P_{i, j}
$$

A correlação é apresentada na Equação 2.4 e mede a correlação dos pixels.

$$
\sum_{i=1}^{L} \sum_{j=1}^{L} \frac{\left(i-\mu_{r}\right)\left(j-\mu_{c}\right) P_{i, j}}{\sqrt{\sigma_{r} \sigma_{c}}}
$$

O contraste é apresentado na Equação 2.5 e mede o contraste local da imagem.

$$
\sum_{i=1}^{L} \sum_{j=1}^{L}(i-j)^{2} P_{i, j}
$$

A Equação 2.6 representa a energia. A Energia mede a ocorrência dos pares repetidos na imagem.

$$
\sum_{i=1}^{L} \sum_{j=1}^{L} P_{i, j}^{2}
$$

A homogeneidade é detalhada na Equação 2.7 e mede a suavidade da textura na imagem.

$$
\sum_{i=1}^{L} \sum_{j=1}^{L} \frac{P_{i, j}}{1+|i-j|}
$$

A ultima medida é a Entropia e é detalhada na Equação 2.8. A entropia mede a aleatoriedade da distribuição dos pixels. 


$$
-\sum_{i=1}^{L} \sum_{j=1}^{L} P_{i, j} \log _{2} P_{i, j}
$$

Os seis valores obtidos são então usados para criar um vetor de características. É possível gerar mais valores repetindo o cálculo com outras matrizes, apenas mudando a relação de ocorrência. Ao final desse processo os vetores gerados podem ser concatenados.

A escolha do extrator de Haralick ocorreu devido a um estudo prévio de Ponti et al. (2015) em que utiliza-se esse extrator em imagens naturais.

\subsubsection{Extrator baseado em Histograma de Gradientes Orientados}

O extrator HOG (do inglês Histograms of Oriented Gradients) foi proposto por Dalal e Triggs (2005) em um estudo de detecção de pessoas. Este extrator extrai a orientação de pequenos blocos nas imagens, e tem como vetor de características um histograma contendo a frequência dos angulos encontrados.

O HoG procura capturar informações referentes ao contorno dos objetos, informações estas que os extratores de cor e textura não capturam. Acreditamos que essas características sejam úteis para diferenciar regiões planas de regiões com maior presença de borda.

Primeiramente o HOG divide a imagem em pequenos blocos a fim de calcular o gradiente orientado. Após o cálculo é então criado um histograma para registrar a ocorrência dos ângulos. O histograma é geralmente quantizado em 18 posições, representando ângulos de 20 graus em cada posição. Depois de normalizado, esse histograma é usado como vetor de característica (Dalal e Triggs, 2005). Um exemplo de imagem analisada pelo HOG pode ser vista na Figura 2.1.

\section{3 Índices de Vegetação}

Os índices de vegetação frequentemente usam operações aritméticas nas bandas do espectro visível, para realçar uma estrutura ou alvo particular. Geralmente esses índices são utilizados com o propósito de realçar a vegetação em imagens, e por isso, em geral, os índices representam um valor real, sendo o mínimo equivalente à água, o máximo equivalente a vegetação densa, e valores intermediários solo, rocha e outros materiais. Esse valor real é posteriormente mapeado para 256 tons de cinza de forma a ser armazenados em imagens com 1 byte por pixel. Assim, dada uma imagem de entrada RGB 24 bits, a saída é uma imagem em escala de cinza de 8 bits. 


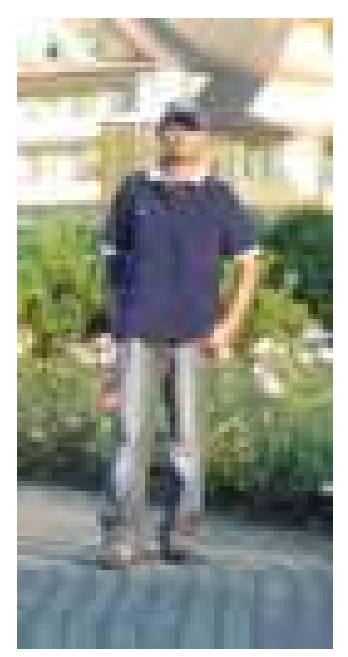

(a)

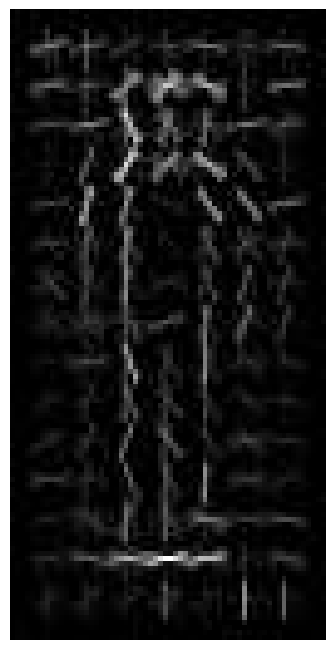

(b)

Figura 2.1: A figura (a) é uma imagem de teste. A figura (b) representa os gradientes descendentes com suas orientações e magnitudes.

Os índices de vegetação usados neste trabalho são os ExG, CIVE e VVI. Existem diversos tipos de índices que utilizam varias informações como infravermelho e ultravioleta próximos, entretanto os índices ExG, CIVE e VVI usam apenas informações do espectro visível, ou seja, imagens RGB. Exemplos de imagens geradas por eles são apresentados na Figura 2.2.

\subsubsection{ExG}

O índice de vegetação ExG (do inglês Excess Green) foi proposto por Woebbecke et al. (1995), em um estudo que comparava cinco índices de vegetação (Meyer e Neto, 2008). O ExG pode ser visto na equação 2.9 .

$$
\mathrm{ExG}=2 g-r-b
$$

O $r, g$ e $b$ são as coordenadas cromáticas fornecidas pela equação 2.10

$$
r=\frac{R *}{R *+G *+B *}, g=\frac{G *}{R *+G *+B *}, b=\frac{B *}{R *+G *+B *}
$$

em que $R *, G *$ e $B *$ são os valores RGB normalizados no intervalo [0,1].

Meyer e Neto (2008) fizeram um estudo com o ExG mais o ExR (do inglês Excess Red). Nesse estudo também foi realizado um estudo comparativo entre outros índices 


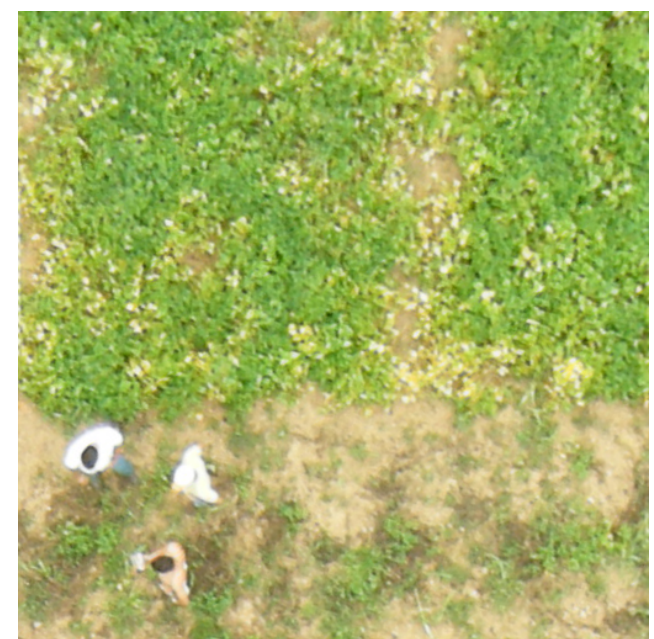

(a)

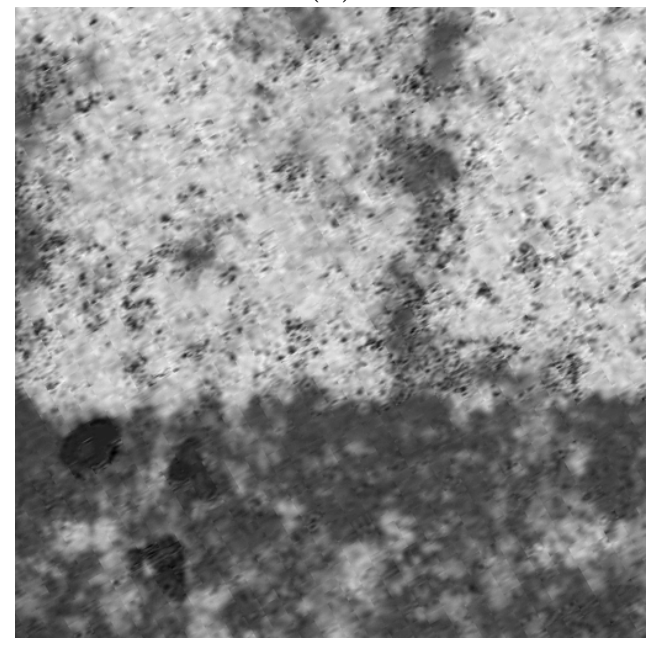

(c)

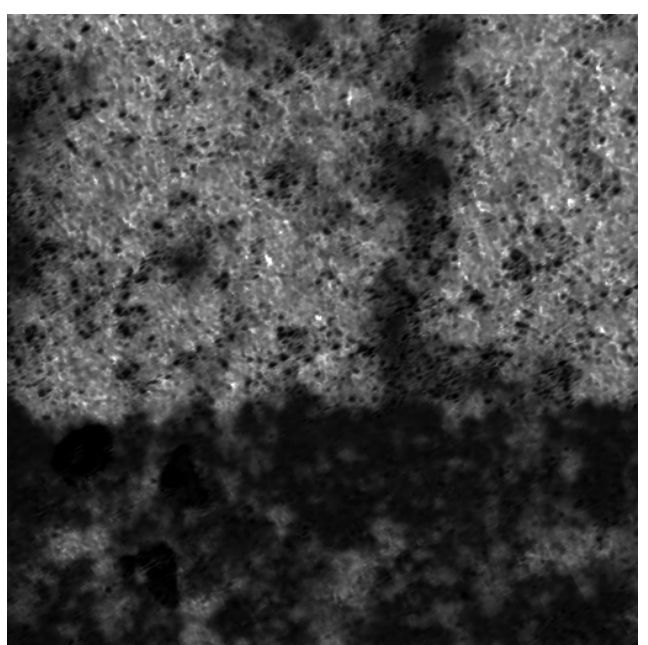

(b)

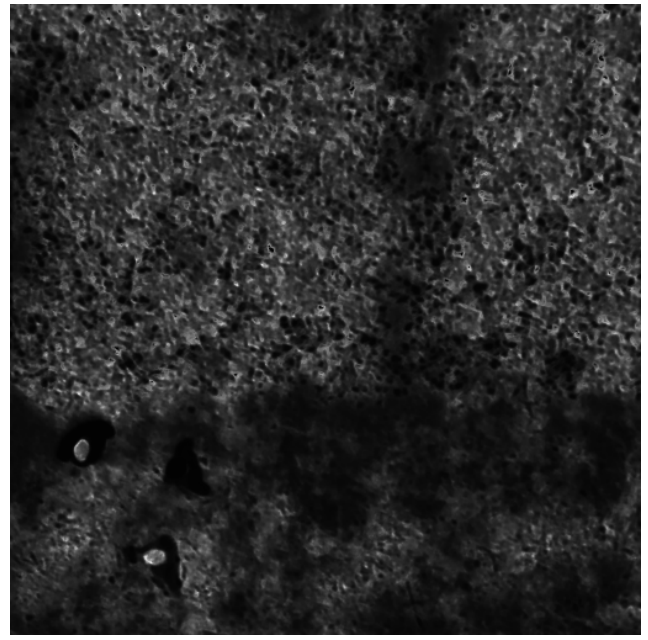

(d)

Figura 2.2: A imagem (a) é a imagem original enquanto (b), (c) e (d) representam as imagens resultantes das técnicas ExG, CIVE e VVI $(w=1)$ respectivamente. 
como o ExG mais limiar de Otsu, e o NDI (do inglês Normalized Difference Index ) que é um índice de vegetação que usa apenas informações do canal $\mathrm{R}$ e $\mathrm{G}$.

\subsubsection{CIVE}

O CIVE (do inglês Color Index of Vegetation Extraction) foi proposto por Kataoka et al. (2003) e é computado na equação 2.11 .

$$
\mathrm{CIVE}=0.441 R-0.811 G+0.385 B+18.787
$$

em que os valores de $R, G$ e $B$ são os valores de intensidade dos pixels RGB.

\subsubsection{VVI}

O índice de Vegetação Visual (VVI - do inglês Visible Vegetation Index) também é uma medida que quantifica a cobertura vegetal verde existente em uma imagem, usando para isso apenas informações do espectro visível (Méndez et al., 2013). O índice VVI é apresentado na equação 2.12 .

$$
\mathrm{VVI}=\left[\left(1-\left|\frac{R-R_{o}}{R+R_{o}}\right|\right) \times\left(1-\left|\frac{G-G_{o}}{G+G_{o}}\right|\right) \times\left(1-\left|\frac{B-B_{o}}{B+B_{o}}\right|\right)\right]^{1 / w}
$$

em que $R, G$ e $B$ são os componentes vermelho, verde e azul respectivamente. $R G B_{0}$ é o vetor de referência para a cor verde, que pode ser alterado de acordo com o domínio alvo. A variável $w$ é um peso exponencial que serve para ajustar a sensibilidade de escala. Usualmente é usado o $R G B_{o}=[40,60,10]$ e o $w=1$ para imagens de 24-bits. Para se evitar divisão por zero, é aconselhado adicionar ao menos o valor 10 nos canais RGB.

\subsection{Considerações Finais}

As técnicas aqui apresentadas serão utilizadas como base para o desenvolvimento do trabalho proposto no Capítulo 4. No próximo capítulo serão apresentados os conceitos de Aprendizado de Máquina, além das formas de se avaliar as bases desbalanceadas. 


\begin{tabular}{l|l}
\hline & Capítulo \\
\hline & 3
\end{tabular}

\section{Aprendizado de Máquina}

\subsection{Considerações Iniciais}

Neste capítulo serão descritos alguns conceitos de Aprendizado de Máquina, com ênfase em aprendizado supervisionado, especificamente os classificadores. Também são descritos conceitos sobre detecção de anomalia e classificadores one-class. Neste capítulo também são apresentados o Aprendizado Ativo e alguns métodos de redução da dimensionalidade de espaços de características. Por fim é descrito o método de avaliação de bases desbalanceadas.

\subsection{Bases Desbalanceadas}

A dificuldade de se trabalhar com bases desbalanceadas está relacionada à quantidade de exemplos pertencentes a cada classe. Quando uma ou mais classes possuem uma quantidade de exemplos significativamente maior que as outras classes, esta base é denominada de base desbalanceada. Por exemplo, em um problema de duas classes, quando a classe positiva possui $70 \%$ dos dados e a classe negativa possui $30 \%$, essa base pode ser considerada uma base desbalanceada. Alguns autores afirmam que uma base é considerada desbalanceada caso uma das classes possua o dobro de elementos em relação à outra classe (Alajlan et al., 2014) (Faceli et al., 2011) (Prati et al., 2014). 
As bases desbalanceadas podem prejudicar o desempenho de vários algoritmos de Aprendizado de Máquina (AM). Devido ao desbalanceamento, esses algoritmos tendem a favorecer a classe com maior quantidade de exemplos, aqui chamada de classe majoritária. O ideal seria corrigir o problema com o rebalanceamento natural, obtendo novos exemplos da mesma fonte dos dados originais, porém em muitas aplicações reais essa abordagem não é viável. Para tentar contornar o problema, existem algumas alternativas como redefinir o tamanho do conjunto de dados, ou treinar um modelo para apenas uma classe.

O tamanho do conjunto de treinamento pode ser redefinido aumentando a quantidade de exemplos da classe minoritária, ou diminuindo os exemplos da classe majoritária. Essas técnicas são conhecidas como técnicas de amostragem. No entretanto, a geração de exemplos artificiais para aumentar a classe minoritária pode gerar o problema de overfitting, no qual o modelo é superajustado aos dados de treinamento. O problema de overfitting ocorre quando o modelo é muito complexo, possuindo vários parâmetros, e superajusta aos dados, podendo capturar informações de ruídos dos dados de treinamento. Por outro lado, eliminar os dados da classe majoritária pode acabar por eliminar os dados importantes para a criação do modelo. Esse problema é denominado underfitting e ocorre quando o modelo treinado não consegue representar os dados de treinamento.

Utilizar classificadores que apenas modelam uma das classes é uma alternativa viável, já que não é preciso se preocupar com os problemas de overfitting e underfitting. Geralmente a classe majoritária, chamada de classe positiva, é usada para o treinamento do modelo.

\subsection{Aprendizado de Máquina}

O Aprendizado de Máquina é uma área da Inteligência Artificial que estuda como os computadores e o homem aprendem através de um ambiente que possui informações rotuladas e/ou não rotuladas. O processo de aprendizado permite realizar indução, no qual obtém-se conclusões genéricas a partir de um conjunto especifico de informação. O aprendizado indutivo, como é chamado, pode ser dividido em duas frentes: aprendizado supervisionado e aprendizado não-supervisionado (Faceli et al., 2011).

Caso os dados sejam rotulados, a tarefa de aprendizado de máquina recebe o nome de aprendizado supervisionado, caso contrário, ou seja, os dados não possuírem rótulos, então esta tarefa passa a receber o nome de aprendizado não-supervisionado. Existem situações em que apenas alguns dados possuem rótulos e o restante não. Nesse tipo de situação, a tarefa é chamada de aprendizado semi-supervisionado. No contexto deste trabalho daremos enfase ao aprendizado supervisionado. 


\subsubsection{Aprendizado Supervisionado}

O aprendizado supervisionado é uma função que, a partir de um conjunto de dados rotulados (classes), constrói um estimador que é usado para estimar o rótulo ou classe de outros dados ainda não rotulados (Faceli et al., 2011) (Domingos, 2012).

Se o domínio dos rótulos são valores discretos então temos um problema de classificação e o estimador recebe o nome de classificador. Caso o domínio seja um conjunto infinito e ordenado de valores temos um problema de regressão, onde o estimador recebe o nome de regressor (Domingos, 2012).

A meta do estimador é encontrar uma fronteira de decisão que separe os exemplos de uma classe dos exemplos da outra. Quando temos duas características, o problema pode ser linearmente separável, nesse caso a fronteira de decisão pode ser uma reta, ou não linearmente separável, nesse caso um conjunto de retas é usado. Quando a quantidade de características é maior que duas, ou seja, a dimensão é maior que dois, a fronteira de decisão é separada através de hiperplanos.

\subsubsection{Support Vector Machine (SVM)}

Uma das técnicas de classificação mais usadas são as Maquinas de Vetores de Suporte, do inglês Support Vector Machines (SVM). Foram propostas por Vapnik (1995) a partir de estudos iniciados em Vapnik e Chervonenkis (1971), e são embasadas pela teoria de aprendizado estatístico, que estabelece uma série de princípios que devem ser seguidos para a obtenção de classificadores com uma boa capacidade de generalização (Burges, 1998) (Faceli et al., 2011).

As SVMs lineares definem fronteiras lineares a partir de dados de treinamento linearmente separáveis. Seja $T$ um conjunto de treinamento com $n$ objetos $x_{i} \in X$ e seus respectivos rótulos $y_{i} \in Y$, no qual $X$ é o espaço de entrada e $Y=\{-1,+1\}$ são as classes existentes. $T$ é linearmente separável se é possível separar os objetos de classes diferentes por meio de um hiperplano.

A definição de um hiperplano é apresentada na Equação 3.1, em que $\mathbf{w} \cdot \mathbf{x}$ é o produto escalar entre $\mathbf{w}$ e $\mathbf{x}$, em que $\mathbf{x} \in X$ e $\mathbf{w} \in X$. O vetor $\mathbf{w}$ representa o vetor normal ao hiperplano e $\frac{b}{\|\mathbf{w}\|}$ corresponde a distância do hiperplano em relação à origem, com $b \in \mathbb{R}$.

$$
h(\mathbf{x})=\mathbf{w} \cdot \mathbf{x}+b
$$

Essa equação do hiperplano pode ser usada para dividir o espaço de entrada $X$ em duas regiões. Por meio de uma função sinal $g(\mathbf{x})=\operatorname{sgn}(h(\mathbf{x}))$ é possível obter a classificação, como visto na Equação 3.2. 


$$
g(\mathbf{x})=\operatorname{sgn}(h(\mathbf{x}))= \begin{cases}+1 & \text { se } \mathbf{w} \cdot \mathbf{x}+b>0 \\ -1 & \text { se } \mathbf{w} \cdot \mathbf{x}+b<0\end{cases}
$$

É definido então o hiperplano canônico em relação ao conjunto $T$, de modo que os exemplos $x_{i}$ mais próximos ao hiperplano $\mathbf{w} \cdot \mathbf{x}+b=0$ satisfaçam a Equação 3.3. Esses exemplos próximos ao hiperplano que ajudam em sua construção são chamados de vetores de suporte.

$$
\left|\mathbf{w} \cdot \mathbf{x}_{i}+b\right|=1
$$

Essa forma gera as inequações 3.4 e na Equação 3.5.

$$
\begin{gathered}
\mathbf{w} \cdot \mathbf{x}+b \geq+1 \quad \text { se } y_{i}=+1 \\
\mathbf{w} \cdot \mathbf{x}+b \leq-1 \quad \text { se } y_{i}=-1 \\
y_{i}(\mathbf{w} \cdot \mathbf{x}+b)-1 \geq 0, \forall\left(\mathbf{x}_{i}, y_{i}\right) \in X
\end{gathered}
$$

A ideia é maximizar a margem separadora a partir do hiperplano separador $\mathbf{w} \cdot \mathbf{x}+b=0$ minimizando a Equação 3.6 com as restrições 3.7.

$$
\begin{gathered}
\operatorname{Minimizar}_{\mathbf{w}, b}=\frac{1}{2}\|\mathbf{w}\|^{2} \\
y_{i}(\mathbf{w} \cdot \mathbf{x}+b)-1 \geq 0, \forall_{i}=1, \ldots, n
\end{gathered}
$$

Essa restrição é aplicada de modo que não haja dados de treinamento entre as margens de separação da classe, sendo por esse motivo chamada de SVM linear de margens rígidas.

Um exemplo de conjunto de dados linearmente separáveis aplicado o hiperplano separador $\mathbf{w} \cdot \mathbf{x}+b=0$ juntamente com as margens $H_{1}$ e $H_{2}$ é apresentado na Figura 3.1

Para problemas reais, em que é difícil encontrar dados linearmente separáveis, foi criada uma extensão das SVMs de margens rígidas, permitindo lidar com conjunto de dados mais gerais. A chamada SVM linear de margens suaves, permite que alguns objetos possam violar a restrição da Equação 3.7, por meio do uso de uma variável de relaxamento $\xi_{i}$ para todo $i=1, \ldots, n$. A Equação 3.8 apresenta a função objetivo reformulada, em que a constante $C$ impõe um peso a minimização dos erros. A nova restrição é apresentada em 3.9 . 


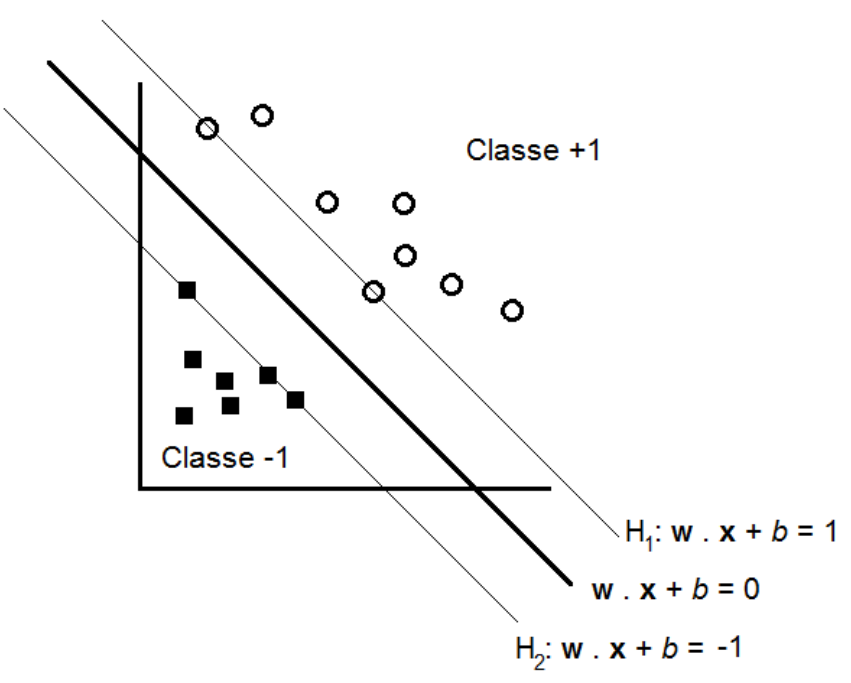

Figura 3.1: Exemplo de conjunto de dados linearmente separáveis com os hiperplanos separador e canônicos. Adaptado de (Faceli et al., 2011).

$$
\begin{gathered}
\operatorname{Minimizar}_{\mathbf{w}, b, \xi}=\frac{1}{2}\|\mathbf{w}\|^{2}+C\left(\sum_{i=1}^{n} \xi_{i}\right) \\
y_{i}(\mathbf{w} \cdot \mathbf{x}+b) \geq 1-\xi_{i}, \xi_{i} \geq 0, \quad \forall_{i}=1, \ldots, n
\end{gathered}
$$

Os métodos citados acima funcionam bem para dados linearmente separáveis, mas quando os dados precisam ser separados por uma função de decisão não linear o SVM se torna incapaz de separar. Nesses casos são utilizados as funções Kernels. A função Kernel mapeia os dados do espaço original, não linearmente separável, para um outro espaço com mais dimensões em que os dados são linearmente separáveis. A Radial basis function (RBF), Polynomyal e Gaussian são exemplos de funções Kernel geralmente utilizadas. (Burges, 1998)

As SVMs possuem uma boa capacidade de generalização, além de serem robustas a objetos de grande dimensão. Outra vantagem é a convexidade do problema de otimização formulado em seu treinamento, que implica a existência de um único mínimo global. Uma das principais limitações das SVMs estão relacionadas à sensibilidade da escolha de seus parâmetros e a dificuldade de interpretação do modelo gerado por essa técnica (Faceli et al., 2011).

No contexto deste trabalho, o SVM foi usado na maioria dos ensaios computacionais descritos no capitulo de metodologia, principalmente os testes envolvendo o aprendizado ativo e a seleção de características. 


\subsubsection{Optimum Path Forest (OPF)}

Papa et al. (2009a) propuseram um classificador denominado Floresta de Caminhos Ótimos, do inglês Optimum-Path Forest (OPF). Algumas das vantagens desse classificador são: classificação de problemas multi-classe nativamente; não necessita parâmetros; não faz nenhuma suposição sobre o formato das classes; e consegue manipular um pouco de sobreposição entre as classes (Papa et al., 2009b). No contexto desse projeto, esse classificador foi utilizado como abordagem para estudo das características visuais dos dados.

A primeira etapa da fase de treinamento consiste em transformar o conjunto de treinamento em um grafo completo, em que cada nó é uma instância e as arestas ligam todos os pares de nós. As arestas possuem pesos que indicam a distância entre dois pares de nós. A distância geralmente usada é a Euclidiana, embora também seja possível utilizar outras distâncias. Em seguida é utilizado o algoritmo Image Foresting Transform (IFT), que é um algoritmo Dijkstra modificado, para criar o grafo de caminhos ótimos.

Após a obtenção desse grafo de caminhos ótimos, é então dado início à segunda etapa da fase de treinamento. Nessa etapa, o algoritmo OPF busca nós que estão mais próximos de classes diferentes. Esses nós são denominados protótipos e representam a região de fronteira entre diferentes classes.

$\mathrm{Na}$ terceira e ultima etapa da fase de treinamento, os protótipos iniciam um processo de competição e conquista das demais instâncias. As instâncias com a menor distância dentre os protótipos concorrentes, passam a pertencer ao caminho ótimo daquele protótipo. $\mathrm{O}$ valor da distância é dada por uma função de custo fmax, que representa o valor da maior aresta ao longo do caminho. Essa função foi escolhida para evitar problemas do tipo cadeia.

Dado que $\left(Z_{1}, A\right)$ é um grafo completo em que os nós são exemplos de treinamento. Um caminho é uma sequencia distinta de exemplos $\pi_{t}=\left\langle s_{1}, s_{2}, \ldots, s_{t}\right\rangle$ que termina em um exemplo $t$. Um caminho trivial é quando $\pi_{t}=\langle t\rangle$. Cada caminho $\pi_{t}$ possui um peso $f\left(\pi_{t}\right)$ dada por uma função de conectividade $f$. Um caminho é dito ótimo se $f\left(\pi_{t}\right) \leq f\left(\pi_{\tau_{t}}\right)$ para qualquer outro caminho $\tau_{t}$. É dito $\pi_{s} \cdot\langle s, t\rangle$ a concatenação de um caminho $\pi_{s}$ com um $\operatorname{arco}(s, t)$. A função de conectividade é apresentada na Equação 3.10, no qual $S$ é o conjunto contendo os protótipos.

$$
\begin{aligned}
& f_{\text {max }}(\langle s\rangle)=\left\{\begin{array}{rr}
0 & \text { se } t \in S, \\
+\infty & \text { caso contrário }
\end{array}\right. \\
& f_{\text {max }}\left(\pi_{s} .\langle s, t\rangle\right)=\max \left\{f\left(\pi_{s}\right), w(s, t)\right\},
\end{aligned}
$$


$\mathrm{Na}$ fase de teste, o exemplo a ser rotulado é inserido na floresta de caminhos ótimos e ligado com todas os outros exemplos. É então verificado qual exemplo do conjunto de treinamento que o conquistou. Após rotular, essa exemplo é removido do grafo, pois não faz parte do conjunto de treinamento, e assim é dado continuidade ao procedimento e análise dos demais exemplos.

\subsubsection{Detectores de Anomalias}

Podemos tratar o problema das bases desbalanceadas como se fossem problemas de detecção de anomalias, principalmente quando a classe normal possui uma distribuição bem definida, enquanto as anomalias provém de diferentes distribuições, dificultando a obtenção de exemplos de treinamento suficientes para treinar um classificador. Uma anomalia é uma observação que difere tanto das demais observações, ao ponto de levantar suspeitas de que ela foi gerada por um mecanismo diferente (Barnett e Lewis, 1994). A tarefa de detecção de anomalia então, tem o objetivo de encontrar esses padrões nos dados, que fogem do comportamento esperado. Dependendo do domínio da aplicação, esses padrões não esperados podem receber o nome de anomalias, outliers, observações discordantes, exceções, aberrações, surpresas, peculiaridades ou contaminantes. Entre os nomes citados, anomalias e outliers são os mais utilizados (Chandola et al., 2009).

Os métodos de detecção de anomalias, em geral, recebem um conjunto de observações e então as separam em dois conjuntos: normais e anômalos. Na maioria das aplicações é comum existir uma predominância de dados classificados como normais e poucos, e as vezes, nenhum anômalo. Por causa desse desbalanceamento entre as classes, muitas vezes não é viável utilizar técnicas convencionais de aprendizado supervisionado. Esse desbalanceamento ocorre, pois na maioria dos casos as anomalias, como o próprio nome já diz, são eventos que ocorrem raramente e são considerados não normais, dificultando assim a observação das mesmas (Costa et al., 2013) (Chandola et al., 2009).

Exemplos de aplicações em que se utiliza a abordagem de deteç̧ão de anomalias incluem detecção de intrusos em redes de computadores (Zhang et al., 2009) (Zhang et al., 2010) ou na detecção de intrusos através do comportamentos inesperados no acesso a banco de dados (Kamra et al., 2008).

\subsubsection{Gaussiana Multivariada (GM)}

O método de Gaussiana Multivariada parte da ideia de que os dados da classe normal foram gerados a partir de uma distribuição Gaussiana. Esta premissa faz sentido quando a classe não anômala possui uma distribuição Gaussiana. Dado $g \in \mathbb{R}$, em que $g$ é 
uma distribuição Gaussiana centrada na média $\mu$ e com variância $\sigma^{2}$, essa distribuição é expressa por $g \sim N\left(\mu, \sigma^{2}\right)$.

Na distribuição Gaussiana Multivariada, temos o vetor média $\mu \in \mathbb{R}^{n}$ e a matriz de covariância $\Sigma \in \mathbb{R}^{n \times n}$, em que a diagonal principal dessa matriz representa as variâncias e os elementos restantes as covariâncias entre as características de uma determinada base de dados.

Primeiramente a técnica estima os parâmetros da distribuição dos dados. Dado um conjunto de treinamento $\left\{x^{(1)}, \ldots, x^{(m)}\right\}$ a estimativa da media é dada pela Equação 3.11 e a estimativa da matriz de covariância é dada pela Equação 3.12.

$$
\begin{gathered}
\mu=\frac{1}{m} \sum_{i=1}^{m} x^{(i)} \\
\Sigma=\frac{1}{m} \sum_{i=1}^{m}\left(x^{(i)}-\mu\right)\left(x^{(i)}-\mu\right)^{T}
\end{gathered}
$$

Após a obtenção do modelo, é possível calcular qual a probabilidade de um novo exemplo ter sido gerado pelo modelo estimado, e isso é feito por meio da Equação 3.13, no qual $|\Sigma|$ é o determinante da matriz $\Sigma$. Caso $p(x)<\varepsilon$ então o exemplo $x$ é detectado como anomalia.

$$
p(x ; \mu, \Sigma)=\frac{1}{(2 \pi)^{\frac{n}{2}}|\Sigma|^{\frac{1}{2}}} \exp \left(-\frac{1}{2}(x-\mu)^{T} \Sigma^{-1}(x-\mu)\right)
$$

Essa técnica que utiliza Gaussiana Multivariada possui uma restrição que é $m>n$, na qual o numero de exemplos $(n)$ tem que ser maior que o numero de dimensões $(d)$. Caso $n \leq d$, a Gaussiana multivariada não pode ser usada já que não é possível calcular a inversa de $\Sigma$.

\subsection{Aprendizado Ativo}

O Aprendizado Ativo (AA), também chamado de Active Learning ou Query Learning, é uma abordagem que assume que, se o algoritmo de aprendizado de máquina é capaz de escolher quais os dados ele irá aprender, ele terá uma melhor performance com um menor custo de treinamento (Settles, 2009) (Wang e Hua, 2011). Na área de sensoriamento remoto, em que as bases geralmente apresentam um certo grau de desbalanceamento, usa-se aprendizado ativo a fim de melhorar o desempenho da classificação (Alajlan et al., 2014) (Demir e Bruzzone, 2015) (Wan et al., 2015) (Tuia et al., 2011). 
O algoritmo de aprendizado ativo deve propor perguntas referente a dados que ainda não foram analisados. Essas perguntas são feitas para um usuário especialista, que tem a função de rotular esses dados.

O aprendizado ativo é comumente utilizado junto ao aprendizado semi-supervisionado. Deste modo, o processo de treinamento e análise fica assim: uma pequena amostra anotada é fornecida ao algoritmo semi-supervisionado, na qual pelo menos uma instância de cada classe deve possuir anotação. Isso permite que o algoritmo identifique e agrupe dados com características semelhantes, criando assim um modelo. É possível classificar os novos dados ainda sem rótulos por meio desse modelo, e assim ir atualizando o mesmo.

Após o término do algoritmo semi-supervisionado, o algoritmo de aprendizado ativo analisa os dados que ainda não foram rotulados, e procura dentre eles aquele que fornecerá o maior ganho de informação para o modelo. Este dado ainda sem anotação é então enviado para um especialista rotulá-lo. Esse processo de aprendizado ativo é detalhado no diagrama da Figura 3.2 (Settles, 2009).

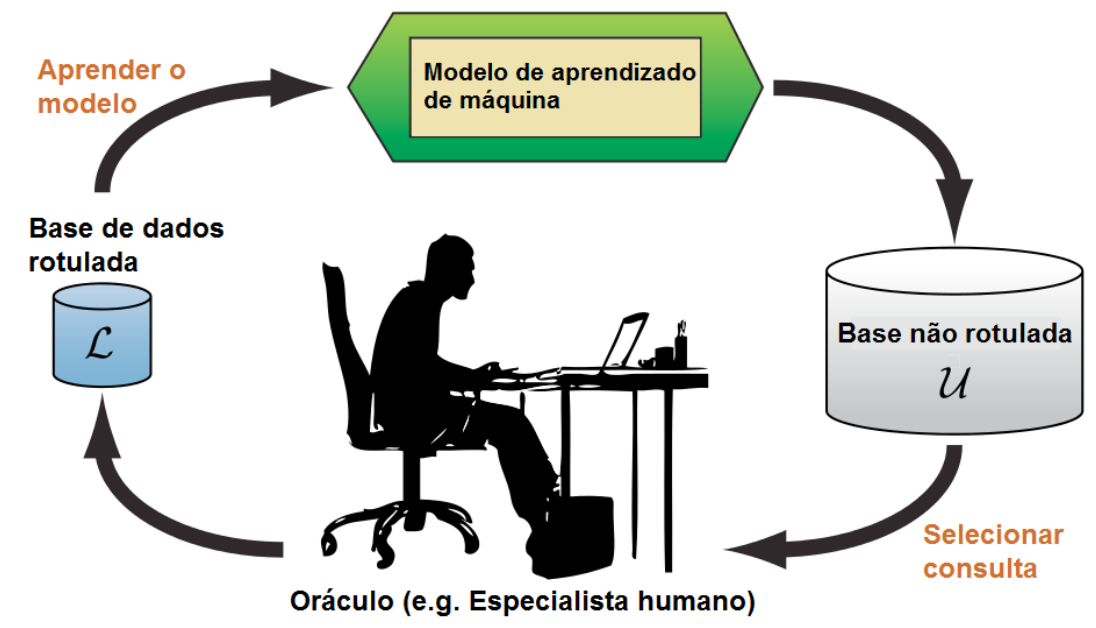

Figura 3.2: Ciclo do aprendizado ativo pool-based (Settles, 2009).

Um aspecto importante a respeito do aprendizado ativo é a qualidade do rótulo. Às vezes os rótulos são originados de experimentos empíricos, como estudos químicos, biológicos e clínicos, e é comum esperar ruído dos equipamentos usados. Com as pessoas não é diferente, e a qualidade do processo de rotular é comprometida por diversos motivos. Várias situações em que pessoas são envolvidas podem resultar em uma baixa qualidade dos rótulos. Primeiramente algumas instâncias são difíceis de rotular, mesmo para os especialistas. Normalmente são utilizados mais do que um especialista para rotular, geralmente um numero impar, e.g.: 3 ou 5, a fim de não causar empates nos votos. Outro motivo que pode gerar ruídos nos rótulos, é que as pessoas podem se cansar ou 
se distraírem, podendo assim diminuir a qualidade dos rótulos. Tendo isso em mente, é importante garantir a robustez dos algoritmos de aprendizado ativo. Para tentar amenizar os ruídos dos oráculos, é importante que o algoritmo de aprendizado ativo faça o mínimo possível de requisições ao especialista, mantendo a precisão (Settles, 2009).

\subsubsection{Heurísticas}

A Heurística de aprendizado ativo tradicionalmente usada é a chamada Margin Sample (MS). Essa heurística foca em selecionar os exemplos próximos ao limiar de decisão do classificador, pois eles são os exemplos que produzem maior indecisão e que trariam maior benefício para o modelo se conhecido o seu rótulo verdadeiro (Tuia et al., 2011) (Alajlan et al., 2014) (Wan et al., 2015).

Com o argumento de que a distribuição das classes poderia mudar do conjunto de treinamento para o conjunto de teste, o trabalho de Alajlan et al. (2014) apresenta algumas alternativas ao MS como a heurística Ran e a Clu. Essas abordagens sugerem que exemplos importantes estão em outras regiões do conjunto de teste, e não apenas perto da margem de decisão. A abordagem Ran consiste em selecionar aleatoriamente exemplos não rotulados a fim de melhorar o modelo. Já a abordagem Clu divide o conjunto de treino em $P$ clusters, em que $P$ também representa o número de exemplos a serem selecionados, e aleatóriamente um exemplo é selecionado em cada cluster. Dessa maneira, a heurística de Clu seleciona exemplos de todo o espaço (Alajlan et al., 2014).

\subsubsection{Aplicações}

O trabalho de Alajlan et al. (2014) foi um estudo de diversas heurísticas de aprendizado ativo em bases de imagem de sensoriamento remoto obtidas com uma resolução espacial de $1 \mathrm{~km}$. Nesse estudo foram utilizadas cinco bandas das imagens obtidas pelo sensor MODIS. Além disso foi utilizado o NDVI (do inglês Normalized Difference Vegetation Index) que faz uso da banda de infra-vermelho próximo para gerar um índice de vegetação. O problema que esse estudo atacou, envolvia a mudança de dominio, que nesse caso eram classes que apareciam poucas vezes no conjunto de treinamento, mas que no conjunto de teste essas classes eram abundantes (Alajlan et al., 2014).

O trabalho de Bietti (2012), denominado "Active Learning for Object Detection on Satellite Images", apresenta a utilização de técnicas de aprendizado ativo na detecção objetos visuais em imagens de satélites. O classificador utilizado foi um SVM linear e a heurística de aprendizado ativo usada foi a MS. Uma ilustração desse estudo é apresentado na Figura 3.3 (Bietti, 2012). 

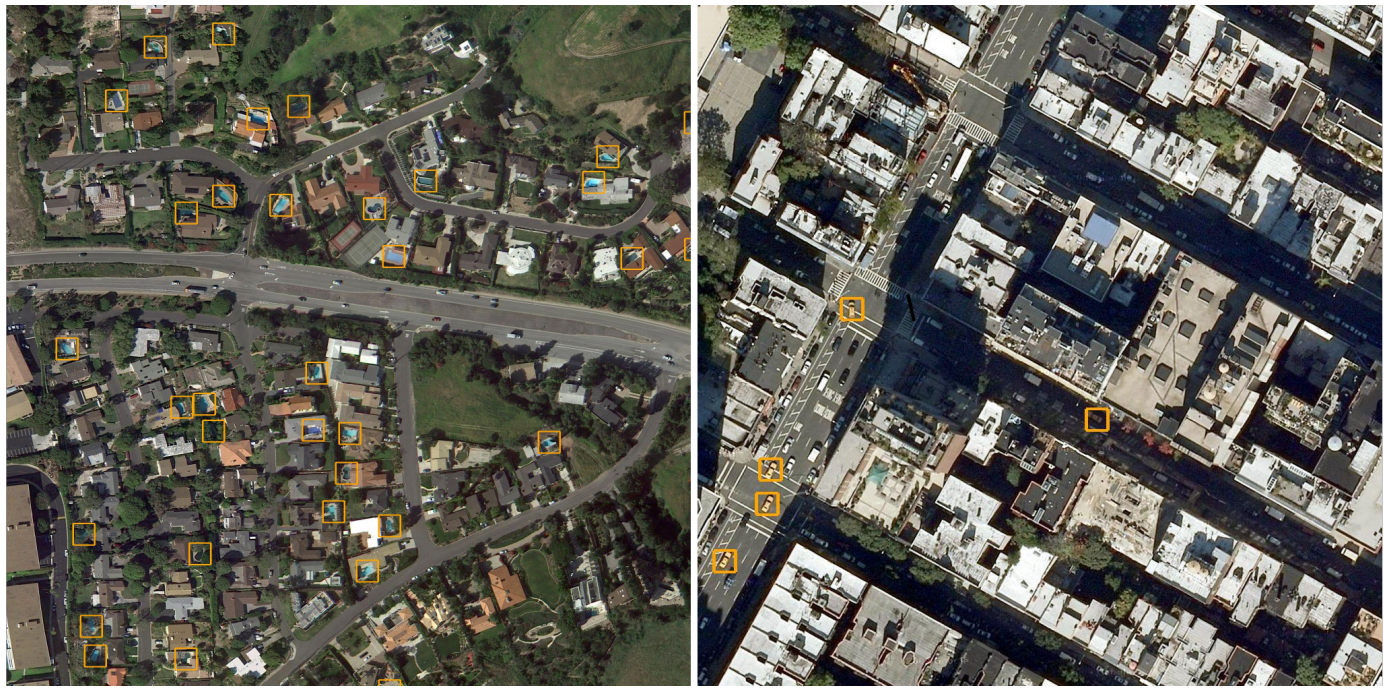

Figura 3.3: Imagens de satélites. Detecção de piscinas no lado esquerdo e de táxis amarelos no lado direito (Bietti, 2012).

Um outro trabalho proposto por Abramson e Freund (2004), usa o aprendizado ativo para detectar pessoas em imagens. A câmera usada para a captura das imagens foi acoplada na frente de um automóvel, e o sistema era usado para detectar quando uma pessoa cruzava a frente do veículo (Abramson e Freund, 2004).

\subsection{Seleção e Transformação de Características}

Um grande número de características não significa necessariamente que o desempenho dos classificadores também melhore, pelo contrário, com o efeito da maldição da dimensionalidade o desempenho tende a piorar. Se cada dimensão for observada como uma coordenada em um espaço $d$-dimensional, em que $d$ é a quantidade de dimensões, o volume que representa esse espaço cresce exponencialmente (Bellman e Bittner, 1962) (Faceli et al., 2011).

Outro problema que se pode identificar em uma base com muitas características, é a correlação existente entre suas dimensões. Muitas vezes existem muitas dimensões discriminantes, porém elas são correlatas, não fornecendo ganho para o modelo.

A solução para esses problemas é utilizar técnicas de redução de dimensionalidade. Essas técnicas podem combinar as características existentes, ou apenas selecionar um subconjunto. Poucas dimensões também trazem outros benefícios como: reduz o tamanho necessário da amostra; simplifica o modelo gerado; facilita visualização; melhora a eficiência computacional. As técnicas de redução de dimensionalidade mais comuns podem ser divididas em duas abordagens: Agregação e Seleção de Atributos. 


\subsubsection{Transformação de Características}

A agregação ou projeção transforma os dados e combina as dimensões por meio de funções lineares e não-lineares. Essas transformações mapeiam dados de um espaço com muitas dimensões para um espaço com poucas dimensões, buscando preservar as relações de similaridade ou vizinhança do espaço original. Esse tipo de abordagem de redução de dimensionalidade possui perda de informação por justamente combinar as características (Paulovich e Minghim, 2008).

Uma técnica foi proposta por Paulovich et al. (2010) e é denominada de Part Linear Multidimensional Projection (PLMP). Essa técnica faz o mapeamento dos espaços usando para o cálculo uma matriz que contém as relações de distâncias. Essa técnica começa projetando uma amostra dos dados e, em seguida é realizado um mapeamento linear para projetar os exemplos restantes.

Outra técnica de projeção é a Local Affine Multidimensional Projection (LAMP), proposta por Joia et al. (2011). Esta técnica, como a PLMP, projeta inicialmente uma amostra dos dados, aqui chamada de pontos de controle. Na LAMP, esses pontos de controle podem ser manipulados pelo usuário, e após essa etapa os exemplos restantes são projetados.

O algoritmo mais conhecido de agregação é a Análise de Componentes Principais (PCA, do inglês Principal Component Analysis) (Pearson, 1901) (Hotelling, 1933). Cada nova dimensão agregada recebe o nome de componente principal, e a quantidade de componentes principais é igual ou menor que a quantidade de dimensões originais. Os componentes principais são ordenados, onde o primeiro componente possui a maior variância, e assim sucessivamente, sendo possível selecionar apenas um subconjunto deles (Jolliffe, 2002).

Um problema das técnicas de agregação é que, ao combinar as dimensões, a visualização é dificultada. Já que não existe mais a interpretação original das dimensões, isso dificulta o entendimento do usuário. O ponto positivo dessas técnicas é que elas reduzem e às vezes até eliminam a correlação entre as dimensões.

\subsubsection{Seleção de Características}

O processo de seleção de características indica quais delas trazem maior benefício para o modelo. Diferente da agregação, a seleção não transforma os dados, apenas encontra um subespaço das características existentes, e nos permite: identificar características importantes; eliminar dimensões redundantes ou irrelevantes; eliminar dimensões que contenham ruído; simplificar o modelo gerado e tornar mais fácil seu entendimento e 
visualização (Faceli et al., 2011) (Murty e Devi, 2011) (Dash e Liu, 1997). Os métodos de seleção de características são divididos em:

- Embutidos;

- Baseados em filtros;

- Baseados em wrappers.

Os métodos embutidos são técnicas vinculadas aos algoritmos de AM, como por exemplo as características selecionadas por um algoritmo de árvore de decisão. Já as técnicas baseadas em filtros realizam uma filtragem na etapa de pré-processamento, selecionando assim um subconjunto de características. Por não possuir uma interação com algoritmos de AM, as técnicas baseadas em filtros podem gerar classificadores com um baixo desempenho. As técnicas de seleção baseadas em wrappers por sua vez tem essa interação com os algoritmos de AM. Os wrappers são técnicas de força bruta que realizam diversas combinações de dimensões, e tentam assim encontrar a combinação ideal que reduza a taxa de erro e que tenha a menor quantidade de dimensões (Dash e Liu, 1997) (Sánchez-Maroño et al., 2007).

Outra maneira de selecionar características é utilizar técnicas de Ordenação. Essas técnicas analisam as características, e assim geram um ranking das características, usando para isso algum critério de ordenação. Nesta abordagem, os primeiros atributos dessa ordenação são selecionados. Esses critérios de ordenação podem ser medidas de similaridades, ou medidas que avaliam as diferenças entre as características, como por exemplo o critério de Fisher (Murty e Devi, 2011). Essas medidas podem usar ou não a informação das classes (Faceli et al., 2011).

\subsection{Métricas de Avaliação em Bases Desbalanceadas}

Em problemas envolvendo bases desbalanceadas, é necessário escolher com atenção as medidas de avaliação de desempenho. Medidas de avaliação tradicionais não consideram o desbalanceamento do conjunto de treinamento, e muitas vezes retornam valores errados, indicando um bom desempenho sendo que na verdade é o contrário.

\subsubsection{Acurácia Balanceada}

Uma medida já conhecida e fortemente empregada na avaliação de algoritmos de classificação é a taxa de acerto ou acurácia do classificador. Ela é uma medida de desempenho 
usualmente empregada para avaliar um classificador $\hat{f}$, onde quanto mais próximo do valor 1 o resultado melhor é o classificador. A acurácia é a soma dos valores da diagonal principal da matriz de confusão, dividido por $n$ que é a quantidade total de elementos. A Equação 3.14 define essa taxa, em que $V P$ é a quantidade de Verdadeiro Positivo e $V N$ é a quantidade de Verdadeiro Negativo (Faceli et al., 2011).

$$
\operatorname{Ac}(\hat{f})=\frac{V P+V N}{n}
$$

O problema é que a acurácia não assume o desbalanceamento entre as classes. Para contornar esse problema essa medida foi adaptada para ficar mais robusta ao desbalanceamento. A nova medida se chama acurácia balanceada e é dada pela média aritmética entre a Sensibilidade e Especificidade. A Sensibilidade corresponde a taxa de acertos da classe positiva e é dada pela Equação 3.15. A Especificidade corresponde a taxa de acertos na classe negativa dada pela Equação 3.16. FN e FP é a quantidade de Falsos Negativos e Falsos Positivos respectivamente. A acurácia balanceada (Acb) é dada pela Equação 3.17 (Velez et al., 2007).

$$
\begin{gathered}
\operatorname{sens}(\hat{f})=\frac{V P}{V P+F N} \\
\operatorname{esp}(\hat{f})=\frac{V N}{V N+F P} \\
\operatorname{Acb}(\hat{f})=\frac{\operatorname{sens}(\hat{f})+\operatorname{esp}(\hat{f})}{2}=\frac{\left(\frac{V P}{V P+F N}\right)+\left(\frac{V N}{V N+F P}\right)}{2}
\end{gathered}
$$

Em todos os testes computacionais deste estudo, foram usados a acurácia balanceada como métrica de desempenho.

\subsection{Considerações Finais}

As técnicas aqui apresentadas serão utilizadas como base para o desenvolvimento da metodologia proposta no Capítulo 4. Muitas das técnicas aqui propostas serão comparadas umas com as outras a fim de definir as melhores técnicas. 


\begin{tabular}{l|l} 
Capítulo \\
\cline { 1 - 1 }
\end{tabular}

\section{Metodologia}

\subsection{Considerações Iniciais}

Neste capítulo são descritas as imagens, as técnicas e os métodos usados nos experimentos. Primeiramente é detalhada a base de dados e como ela foi obtida. Em seguida foi descrito como foi realizada a extração de características das imagens da base e os ensaios computacionais a fim de identificar o melhor modo de realizar a extração. Na Seção 4.3 são detalhadas as formas de seleção de características e apresentados os pipelines propostos. Na Seção 4.4 é descrita a análise com a técnica de redução de dimensionalidade PCA. Todos os testes desta seção foram avaliados utilizando a acurácia balanceada como medida de desempenho.

\subsection{Base de imagens de cobertura vegetal}

Imagens de sensoriamento remoto de cobertura vegetal são usadas para tomadas de decisão na agricultura, por meio da agricultura de precisão. Muitas das pesquisas nessa área são voltadas para o uso de imagens de satélites, que muitas vezes são caras e/ou não possuem a resolução e o detalhamento adequados (Moran et al., 1997) (Zhang et al., 2002).

Uma alternativa comercialmente viável para se obter imagens aéreas, porém com uma resolução maior das de satélites é o sensoriamento remoto suborbital onde é possível usar 
drones, balões ou VANTs(Veículo Aéreo Não Tribulado) para essa tarefa (Verhoeven et al., 2009).

\subsubsection{Aquisição da base de dados}

A base de cobertura vegetal é composta por 40 imagens aéreas de plantação de feijão. O sistema de aquisição das imagens foi construído utilizando um balão de hélio de modelo Skyhook Helikite ${ }^{T M}$. O equipamento combina partes de um balão de gás hélio com uma pipa como apresentado na Figura 4.1. Este estilo de equipamento se mostrou uma alternativa de baixo custo para aplicações de sensoriamento remoto suborbital (Verhoeven et al., 2009). O equipamento possui a forma similar aos dirigíveis para um melhor controle e estabilidade. Uma câmera digital com um sensor CCD de 10 Megapixels de tamanho $1 / 2.3^{\prime \prime}$ foi acoplado ao balão. Apenas os canais visíveis foram adquiridos nesse sistema, ou seja, as imagens capturadas são todas imagens de 24 bits RGB. As imagens estão disponíveis para download ${ }^{1}$ junto com seus ground truth.

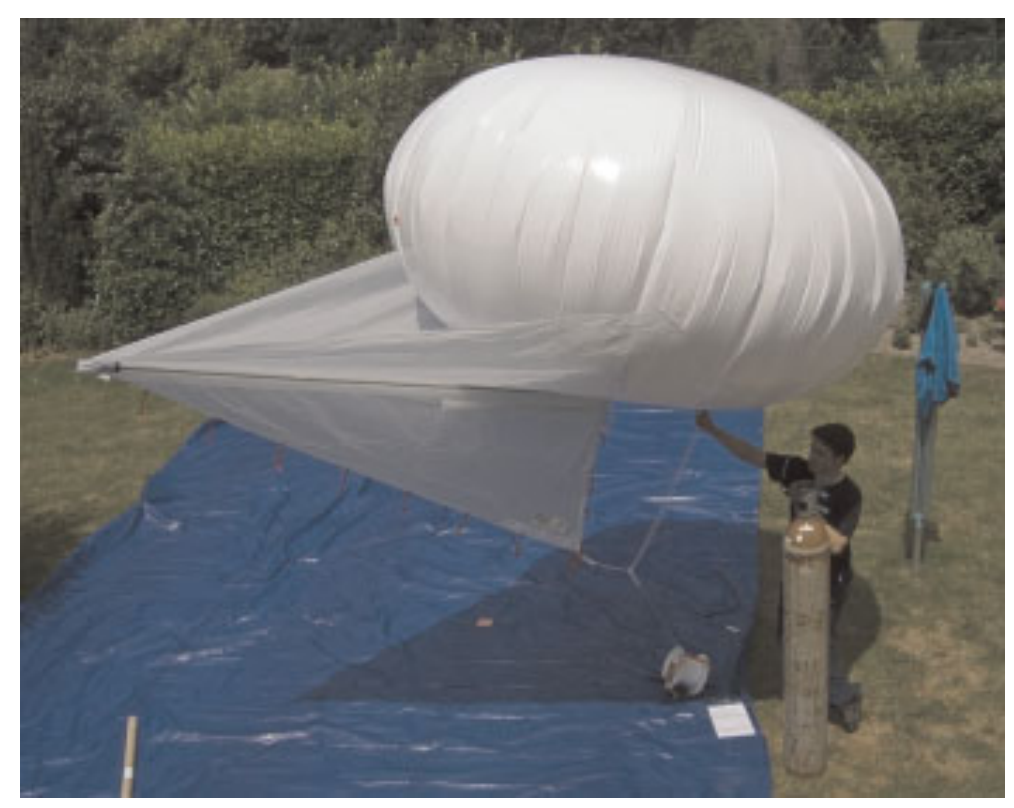

Figura 4.1: Helikite de modelo Skyhook (Verhoeven et al., 2009).

As 40 imagens foram capturadas de uma altura de aproximadamente 50 metros. São imagens obtidas de duas diferentes culturas de feijão, 63 dias depois do surgimento das plantas. As imagens foram recortadas para obter parcelas de $512 \times 512$ pixels, resultando em uma resolução aproximada de $2.1 \mathrm{~cm} /$ pixel. Das 40 imagens, 18 foram obtidas da cultura 1 que é a cultura mais produtiva, e as 22 imagens restantes foram obtidas da

\footnotetext{
${ }^{1}$ As imagens e seus ground truth estão disponíveis em http://www.icmc.usp.br/pessoas/moacir/ data/
} 
cultura 2 que possui um solo mais compacto e por isso menos produtiva (Ponti, 2013). A Figura 4.2 apresenta exemplos de imagens do dataset com seus respectivos rótulos (ground truth).
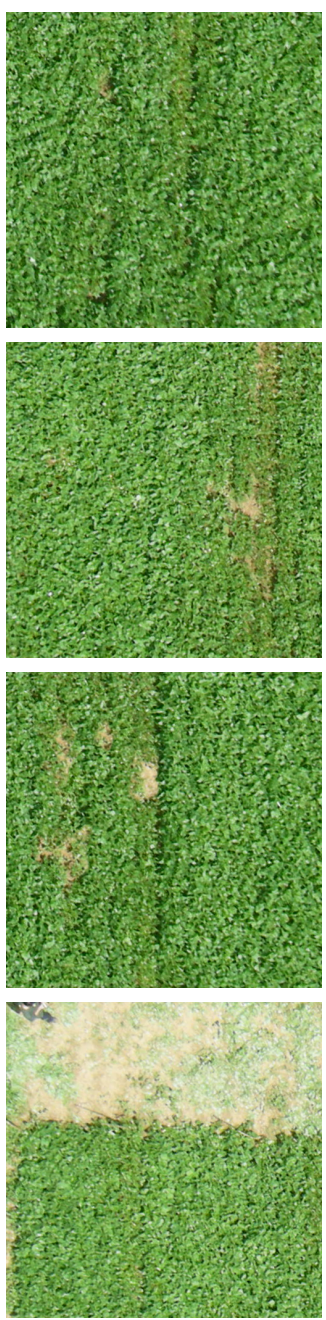

(a)
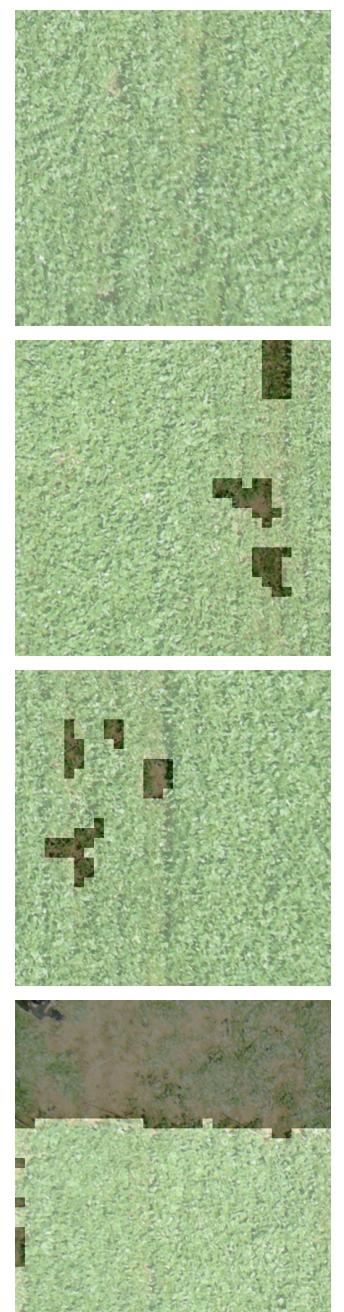

(b)
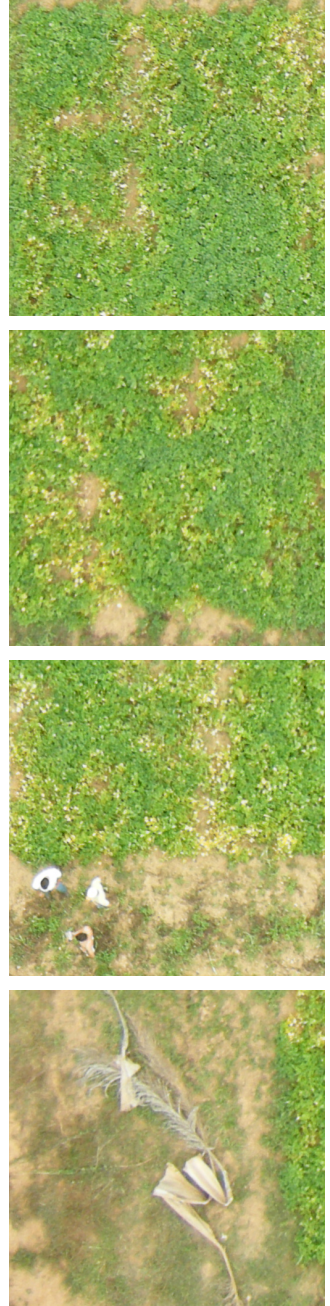

(c)
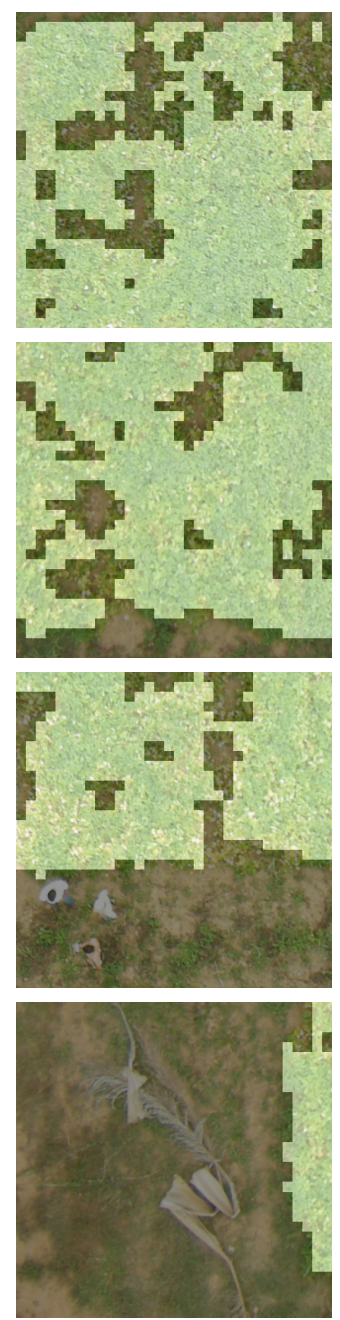

(d)

Figura 4.2: Exemplos de imagens obtidas das duas diferentes culturas. As imagens da coluna (a) e (b) são imagens da cultura 1; (c) e (d) são da cultura 2. As imagens (a) e (c) representam as imagens RGB, e as imagens (b) e (d) representam o ground truth em que as regiões iluminadas representam os rótulos positivos (cobertura vegetal) e as regiões escuras os rótulos negativos.

Para obter o ground truth das imagens, três engenheiros agrônomos registraram os rótulos de cada região de $16 \times 16$ pixels da imagem. Eles indicavam se pertenciam à classe positiva ou à classe negativa. Exemplos da classe positiva são todas as porções de imagem que são consideradas cobertas por plantas de feijão. Os exemplos da classe negativa são todos aquelas porções de imagens que são solo, pouca cobertura vegetal ou qualquer outro 
objeto. A classe negativa também é denominada de anomalia. Esse processo resultou em 1024 rótulos para cada imagem de $512 \times 512$ pixels da base de dados, totalizando em 40960 rótulos para toda a base.

A concordância média entre os especialistas na etapa de rotular foi de $93.7 \%$. Depois de rotular, o ground truth das regiões de $16 \times 16$ foi decidido pelo voto majoritário. A proporção de cada classe no banco de dados final é de 29556 (72.2\%) exemplos da classe positiva e 11404 (27.8\%) exemplos da classe negativa.

Essa base de dados possui um certo grau de desbalanceamento, contendo mais que o dobro de classes positivas em comparação às negativas. Outra observação importante, é referente ao grau de desbalanceamento contido em cada imagem, ou seja, se os 1024 rótulos de cada imagem são balanceados. Nessa base existem situações em que as imagens contem $100 \%$ dos rótulos pertencentes à classe de cobertura vegetal, como também existem imagens contendo quase todos os rótulos pertencentes à classe de não cobertura vegetal. Esse comportamento da base de imagens, apresenta um ambiente muito severo para os algoritmos de aprendizado de máquina atuarem. Para esse tipo de desbalanceamento não atrapalhar o desempenho da classificação, é necessário um estudo detalhado das características que melhor descriminem a base de dados.

\subsubsection{Extração de Características da base}

As características foram obtidas usando diferentes combinações de índices de vegetação e extratores de características, formando assim diferentes espaços de características. Os índices de vegetação usados foram o ExG, CIVE e VVI, esse último foi usado duas vezes com o parâmetro $w=1$ e $w=10$. Os extratores usados foram o BIC para cor, o HOG para orientação de gradientes e o Haralick para textura. O vetor gerado pelo HOG possui 18 posições com 20 graus para cada posição. O vetor de características do Haralick foi obtido calculando 8 matrizes de co-ocorrência diferentes, cada uma com uma relação entre pixels diferentes, variando os ângulos dos 8 vizinhos do pixel referência.

Primeiramente foram calculados os índices de vegetação para cada imagem de $512 \times$ 512 , e em seguida essas imagens foram divididas em sub-imagens de $16 \times 16$, já que os rótulos fornecidos pelo ground truth possuem o mesmo tamanho. Com essa divisão foram geradas 1024 sub-imagens para cada imagem de $512 \times 512$ da base original. Neste trabalho, ao se referir a uma imagem da base, também está se referindo às 1024 sub-imagens referentes a essa imagem. Em seguida, o vetor de características foi computado para cada sub-imagem gerada pelos índices de vegetação. Foram usados os extratores BIC, HOG e Haralick, para cada imagem de índice, e por fim, os vetores de características 
gerados foram concatenados para formar apenas um único vetor de características. A Figura 4.3 mostra o processo descrito.

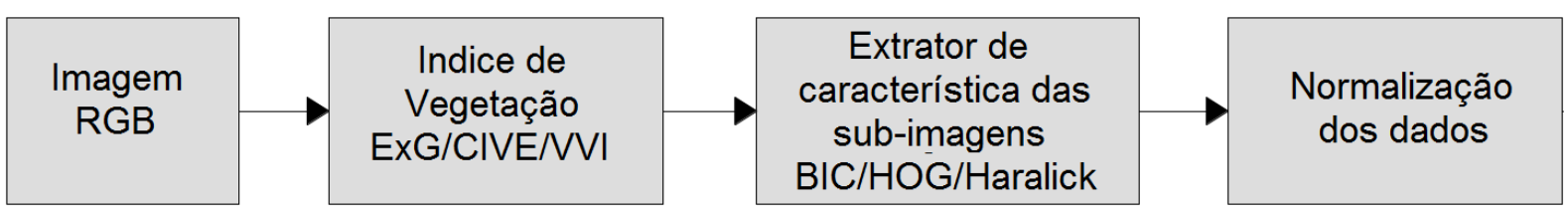

Figura 4.3: Fluxo da extração de características

Para o extrator BIC, as imagens foram quantizadas em 16 níveis de intensidade para se reduzir o tamanho do vetor de característica. No extrator HOG foi usado um histograma com 18 orientações. O extrator de textura Haralick produz 6 valores para cada uma das 8 direções com distância 1 usadas, totalizando assim um vetor com 48 posições. Esses três vetores geram um único vetor de características com 82 dimensões. Por fim, após extrair as características de cada um dos quatro índices de vegetação, os quatro vetores de 82 dimensões são concatenados. O vetor de características final possui 328 dimensões.

Uma etapa importante é o pós-processamento dos dados, que envolve o tratamento dos dados e a normalização dos mesmos. Os vetores foram normalizados de formas diferentes de acordo com a dependência das dimensões. No caso dos extratores de BIC e HOG, devido à dependência entre as dimensões, já que são histogramas, eles foram normalizados em linha, ou seja, a soma dos vetores de cada técnica foi normalizada para que os valores estejam no intervalo de $[0,1]$. No caso do Haralick, em que suas dimensões não são dependentes, a normalização ocorreu em coluna, fazendo com que toda as dimensões fiquem no intervalo de [0,1]. Dado um valor $v$ contido na dimensão $d$, o novo valor normalizado $v^{\prime}$ é calculado usando os valores $\max _{d}$ e $\min _{d}$ dessa dimensão, como apresentado na equação 4.1 .

$$
v^{\prime}=\frac{v-\min _{d}}{\max _{d}-\min _{d}}
$$

\subsubsection{Análise das características da base de dados}

Com o objetivo de entender quais os índices e extratores que melhor representam e discriminem as classes da base, foram conduzidos três experimentos de classificação. $\mathrm{O}$ primeiro para descobrir qual o melhor índice de vegetação e o segundo para descobrir qual a melhor característica visual (cor, textura ou orientação). O terceiro experimento envolveu todas as características comparadas com o melhor índice e o extrator identificados no primeiro e segundo experimento. Nessa fase foram usados os índices CIVE, ExG e 
$\operatorname{VVI}(w=1)$. A ideia é comparar a acurácia da classificação de diferentes espaços de características e identificar qual o melhor.

O algoritmo de classificação usado é o OPF, e ele foi escolhido pois não precisa de ajuste de parâmetros, eliminando a necessidade de definir os parâmetros usando alguma heurística ou busca. A medida de avaliação usada no experimento foi a acurácia balanceada.

No primeiro experimento, cada índice de vegetação é fixo e o vetor composto por todas as características de cor, textura e orientação. Nesse experimento, cada novo subespaço é referenciado a um índice de vegetação, contendo ao todo 82 dimensões cada. Esse processo é ilustrado na Figura 4.4.

\begin{tabular}{|c|c|c|}
\hline \multicolumn{3}{|c|}{ CIVE } \\
\hline $\begin{array}{c}\text { cor } \\
\mathrm{BIC}(16 d)\end{array}$ & $\begin{array}{l}\text { orientação } \\
\text { HoG }(18 d)\end{array}$ & $\begin{array}{l}\text { textura } \\
\text { Haralick }(6 \times 8=48 d)\end{array}$ \\
\hline \multicolumn{3}{|c|}{ ExG } \\
\hline $\begin{array}{c}\text { cor } \\
\operatorname{BIC}(16 d)\end{array}$ & $\begin{array}{c}\text { orientação } \\
\text { HoG }(18 d)\end{array}$ & $\begin{array}{c}\text { textura } \\
\text { Haralick }(6 \times 8=48 d)\end{array}$ \\
\hline \multicolumn{3}{|c|}{$\mathrm{VVI} w=1$} \\
\hline $\begin{array}{c}\text { cor } \\
\operatorname{BIC}(16 d)\end{array}$ & $\begin{array}{c}\text { orientação } \\
\text { HoG }(18 d)\end{array}$ & $\begin{array}{c}\text { textura } \\
\text { Haralick }(6 \times 8=48 d)\end{array}$ \\
\hline
\end{tabular}

Figura 4.4: Formação dos vetores de característica do primeiro experimento

O segundo experimento é similar ao primeiro, porém neste são as características que são fixas enquanto os índices de vegetação são concatenados. Cada extrator de característica extrai uma quantidade diferente de dimensões e, por isso, cada novo subespaço possui tamanhos diferentes. O subespaço BIC produz 48 dimensões, o HOG produz 54 dimensões e o Haralick produz 144 dimensões. Esse processo é mostrado na Figura 4.5.

\begin{tabular}{|c|c|c|c|c|c|}
\hline CIVE & ExG & VVI & CIVE & ExG & $\mathrm{VVI}$ \\
\hline $\begin{array}{c}\text { cor } \\
\operatorname{BIC}(16 d)\end{array}$ & $\begin{array}{c}\text { cor } \\
\mathrm{BIC}(16 d)\end{array}$ & $\begin{array}{c}\text { cor } \\
\mathrm{BIC}(16 d)\end{array}$ & $\begin{array}{c}\text { orientação } \\
\text { HoG }(18 d)\end{array}$ & $\begin{array}{c}\text { orientação } \\
\text { HoG }(18 d)\end{array}$ & $\begin{array}{c}\text { orientação } \\
\text { HoG }(18 d)\end{array}$ \\
\hline \multicolumn{2}{|c|}{ CIVE } & \multicolumn{2}{|c|}{ ExG } & \multicolumn{2}{|r|}{$\mathrm{VVI}$} \\
\hline \multicolumn{2}{|c|}{$\begin{array}{c}\text { textura } \\
\text { Haralick }(6 \times 8=48 d)\end{array}$} & \multicolumn{2}{|c|}{$\begin{array}{c}\text { textura } \\
\text { Haralick }(6 \times 8=48 d)\end{array}$} & \multicolumn{2}{|c|}{$\begin{array}{c}\text { textura } \\
\text { Haralick }(6 \times 8=48 d)\end{array}$} \\
\hline
\end{tabular}

Figura 4.5: Formação dos vetores de características do segundo experimento

O resultado dos dois primeiros experimentos foi usado no terceiro experimento. $\mathrm{O}$ melhor índice e a melhor característica foram comparados com todas as características e todos os índices. 
Cada experimento ocorreu usando repetidas sub amostragens, em 10 repetições, para assim obter a média e o desvio padrão da acurácia balanceada. Em cada repetição, a base de dados foi amostrada randomicamente e separada em $20 \%$ para treinamento, $10 \%$ para validação e $70 \%$ para teste.

\subsection{Seleção de características em bases desbalanceadas}

Muitas vezes, não é possível realizar uma análise visual para se identificar quais as melhores características a serem extraídas em bases de cobertura vegetal. Por essa razão, as características extraídas podem não ser as melhores para se separar os dados de classes distintas. Devido a isso, foi proposta a criação de um pipeline para automatizar esse processo.

De uma forma geral, o pipeline proposto funciona da seguinte forma: Dada uma base de imagens de cobertura vegetal, são realizadas diversas extrações de características. O processo de extração usa os índices de vegetação e os extratores de cor BIC, gradiente orientado HOG e textura Haralick, do mesmo modo que foi detalhado na Subseção 4.2.2. A próxima etapa consiste na seleção por ordenação, em que são selecionadas as $p$ primeiras dimensões do vetor ordenado, em que $p$ é a estimativa do MLE ao analisar a base de treinamento. Após o processo de redução das dimensões, a nova base com as $p$ dimensões é fornecida para o treinamento de um classificador. Esse processo é mostrado na Figura 4.6.

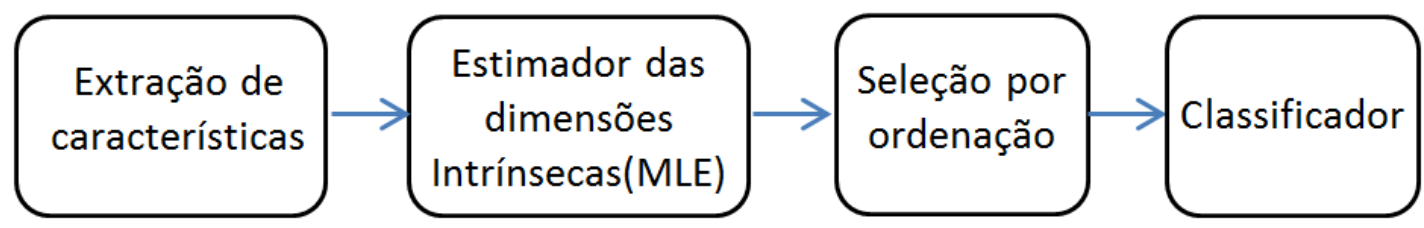

Figura 4.6: Pipeline proposto para automatizar o processo de extração e seleção de características

Os experimentos executados nesta seção fizeram uso da base de dados detalhada na seção anterior. Para relembrar, a base é formada pelos índices de vegetação Exg, CIVE, $\operatorname{VVI}(w=1)$ e $\operatorname{VVI}(w=10)$, e de cada índice foram extraídos características de cor, textura e orientação. O vetor de características possui 328 dimensões e a base de dados contém 40960 exemplos. 


\subsubsection{Seleção por ordenação}

Dada a grande quantidade de dimensões, foram realizados alguns experimentos com seleção de características, para se definir as dimensões intrínsecas na base de dados. Foram propostos três métodos de seleção de características por ordenação. Esses métodos possuem relação com o uso do critério de Fisher, que relaciona a média e o desvio padrão entre classes (Murty e Devi, 2011).

1. Técnica 1: Ordenação pela maior variância independente de classe, ordenando as dimensões de forma decrescente.

2. Técnica 2: Soma da variância intra classe, e esse método ordena as dimensões de forma crescente, ou seja, as dimensões que obteram menor soma das variâncias vêm antes.

3. Técnica 3: Diferença entre as médias de cada classe, e ordenado de forma decrescente para a maior diferença vir em primeiro.

O primeiro método de ordenação pela variância independente da classe, também chamada de técnica $\mathbf{1}$, foi proposto pois, acredita-se que as características que possuem a maior variância são as que contribuem mais no treinamento do classificador. Esse método extraiu a variância de todas as dimensões, independente da classe, e então ordenou de forma crescente, com as maiores variâncias no começo do vetor. A Figura 4.7 mostra a hipótese do primeiro método em que $\operatorname{Var} 1$ e $\operatorname{Var} 2$ são as variâncias das características 1 e 2 respectivamente.

O segundo método, também chamada de técnica 2, leva em conta a soma da variância dependendo da classe. A hipótese é que, se a soma das variâncias dependendo das classes for pequena, isso pode indicar menor sobreposição entre as classes. A ordenação desse método ocorre de forma crescente. Dado que $\sigma_{\omega_{i}}^{2}$ é a variância de uma única dimensão da classe $\omega_{i}$, esse método pode ser representado com a seguinte Equação 4.2.

$$
s v\left(\omega_{1}, \omega_{2}\right)=\left|\sigma_{\omega_{1}}^{2}+\sigma_{\omega_{2}}^{2}\right|
$$

A Figura 4.8 ilustra a hipótese do segundo método em um gráfico bidimensional. Nesse exemplo são usadas duas distribuições gaussianas de duas classes distintas, vermelha e azul, contendo 1000 exemplos cada. Nas imagens (a) e (b), as médias são iguais nas duas classes, com médias $(-2,0)$ e $(2,0)$, porém o desvio padrão da imagem (a) é de 1 para ambas as classes, enquanto na imagem (b) as distribuições possuem valor de 0.6 de desvio 


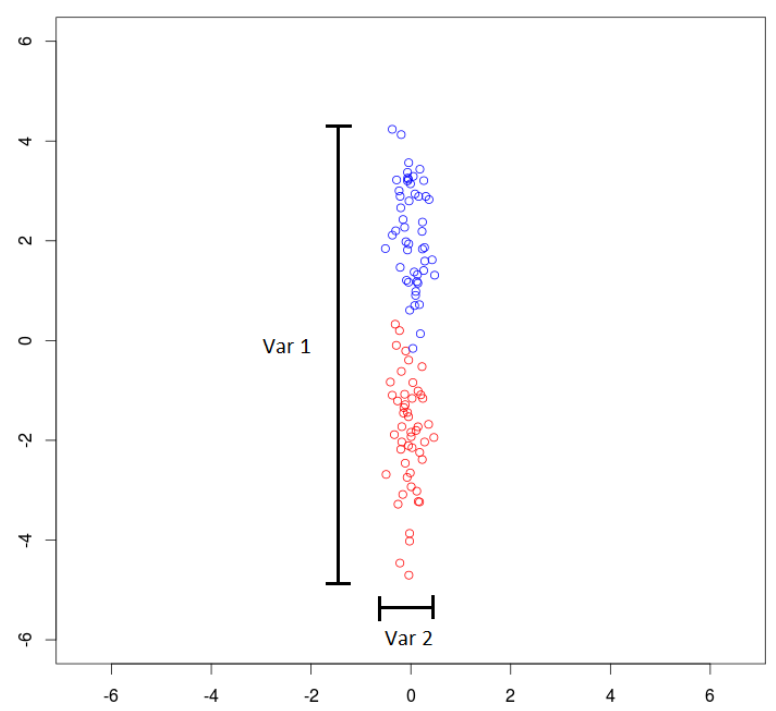

Figura 4.7: Exemplo hipotético. Var 1 é a variância da dimensão 1 e Var 2 é a variância da dimensão 2. A hipótese desse método é que, quanto menor a variância da dimensão, menor são as chances dela de separar os exemplos de classes distintas.

padrão. Comparando a separação dos dados entre as classes da imagem (a) com a imagem (b), é observado que quanto menor a variância, menos sobreposições os dados possuem e por isso mais separados as classes estão.

O terceiro método, ou técnica 3, foi proposto com a hipótese de que, se uma característica possuir uma diferença grande entre as médias, implica que as classes estão separadas o suficiente para minimizar a sobreposição. Dado que $\mu_{\omega_{i}}$ é a média uma única dimensão da classe $\omega_{i}$. A diferença entre a média de cada classe é computada para cada dimensão como apresentada na Formula 4.3.

$$
d m\left(\omega_{1}, \omega_{2}\right)=\left|\mu_{\omega_{1}}-\mu_{\omega_{2}}\right|
$$

O terceiro método é exemplificado na Figura 4.9. Nesse exemplo também são usadas duas distribuições gaussianas de duas classes distintas, vermelha e azul, contendo 1000 exemplos cada. Nessa figura, as distribuições gaussianas presentes nas imagens (a) e (b) possuem a mesma variância de 0.6 para a classe vermelha e 0.3 para a classe azul. O que se altera são as médias das distribuições, que na imagem (a) as médias são $(-5,0)$ e $(5,0)$ enquanto na imagem (b) as médias são $(-1,0)$ e $(1,0)$ para a classe vermelha e azul respectivamente. É observado nesse exemplo que quanto maior a diferença entre as médias, ou seja, quanto mais distante uma distribuição está da outra, mais separados os dados estão. 


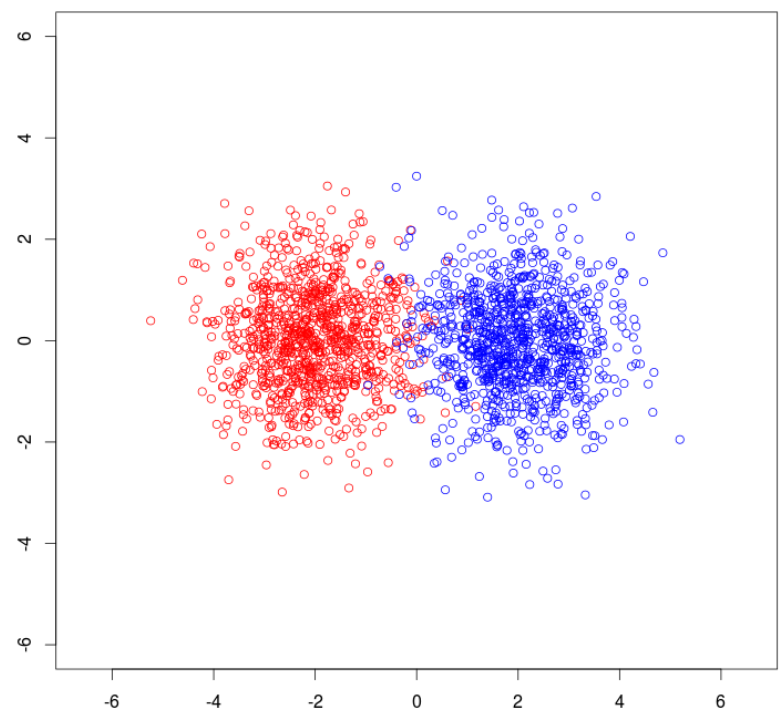

(a)

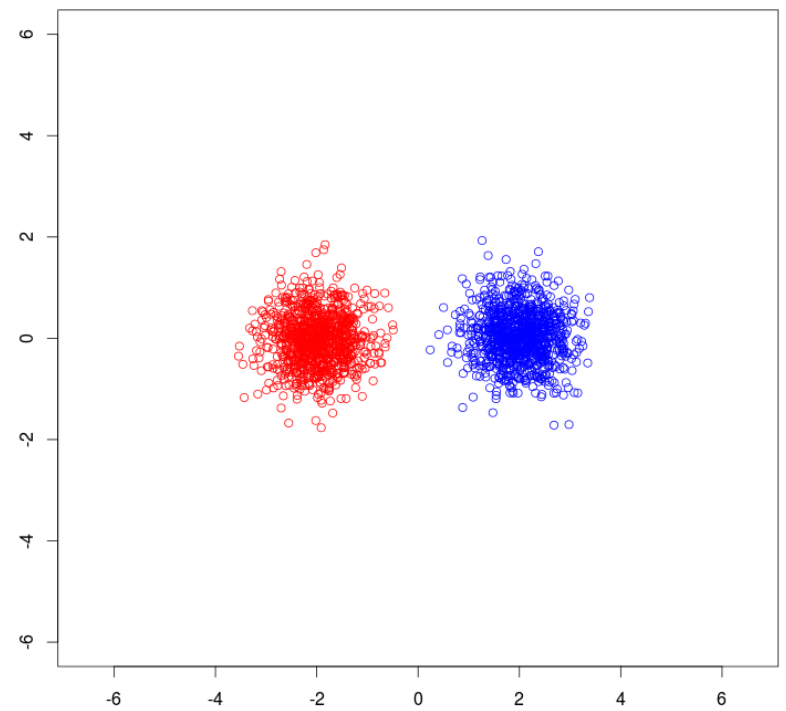

(b)

Figura 4.8: Exemplo hipotético. As imagens (a) e (b) exemplificam duas distribuições gaussianas, de classes vermelha e azul, onde em ambas as imagens as médias são iguais porém os desvios padrões são diferentes. Na imagem (a) o desvio padrão é de 1 enquanto na imagem (b) o desvio padrão é de 0.6. A hipótese é que quanto maior a variância em cada classe, maiores são as chances de sobreposição dos dados das classes distintas. 


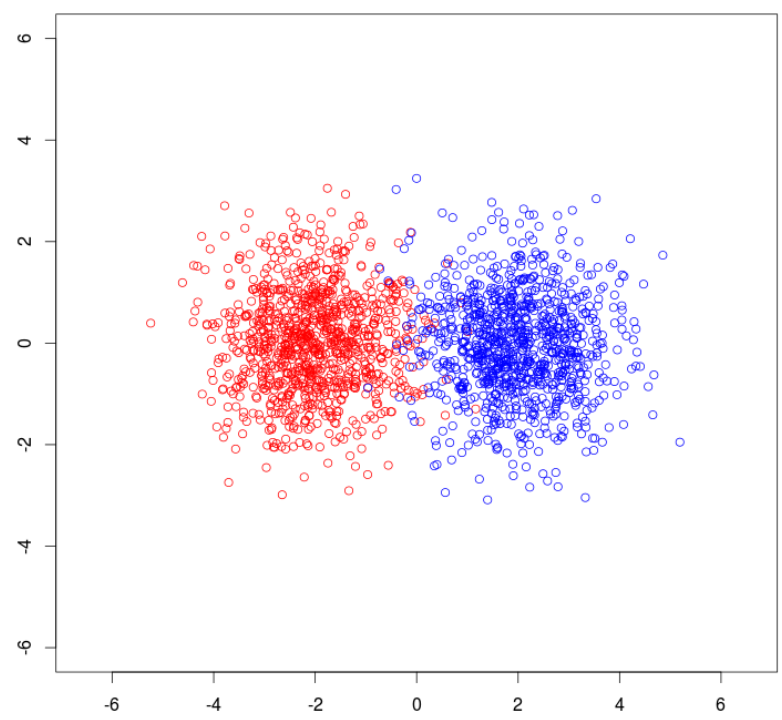

(a)

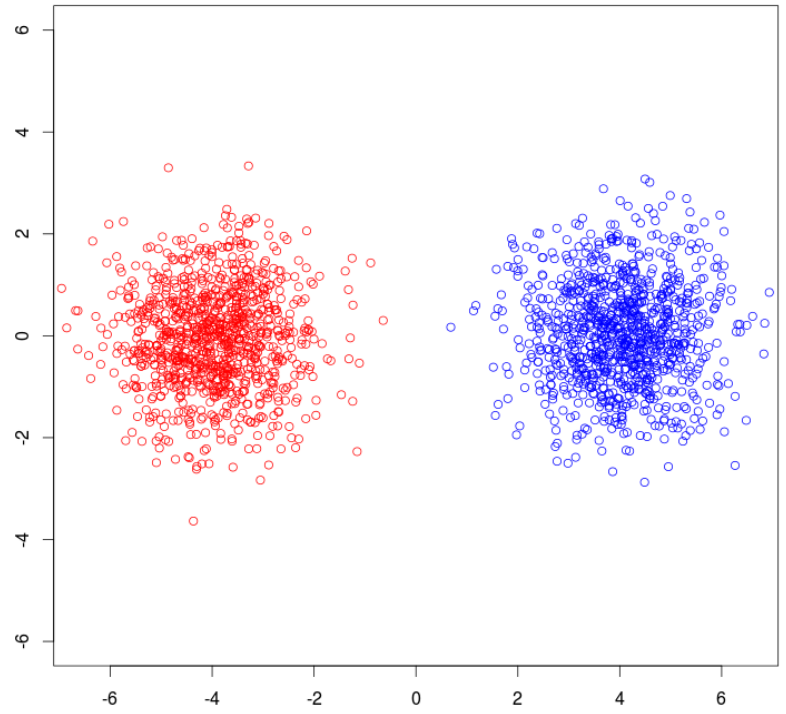

(b)

Figura 4.9: Exemplo hipotético. As imagens (a) e (b) exemplificam duas distribuições gaussianas, de classes vermelha e azul, onde em ambas as imagens os desvios padrões são iguais porém as médias se alteram. Na imagem (a) a média é de $(-5,0)$ e $(5,0)$ enquanto na imagem (b) a média é de $(-1,0)$ e $(1,0)$. É observado que quanto maior o desvio padrão, maiores são as chances de sobreposição entre as classes. 
Todas as figuras apresentadas para exemplificar as técnicas de seleção de características são hipotéticas.

Nessa etapa, é preciso definir qual a melhor técnica de seleção de características por ordenação. Para se definir quantas dimensões seriam usadas do vetor de dimensões ordenado, utilizou-se a técnica MLE, que retorna uma estimativa da quantidade de dimensões intrínsecas. Essa técnica foi usada com o parâmetro $k=10$ para a quantidade de vizinhos, como sugerido pelos autores (Levina e Bickel, 2004).

Nos ensaios computacionais foram usados os algoritmos GM e o SVM. Os parâmetros do SVM foram definidos por meio de uma busca em grid. Também foram realizados alguns testes preliminares com os Kernels do SVM, tal que os Kernels polinomial e radial apresentaram o melhor desempenho.

$\mathrm{Na}$ avaliação foi utilizado o $K$-fold cross validation. O teste ocorreu com $K=40$, 20, 10, 5. Nesse experimento, cada imagem é considerada um conjunto contendo 1024 exemplos. O cross validation separa o primeiro conjunto, ou seja, a primeira imagem, para treinamento enquanto os outros são usados para teste. Na segunda iteração o segundo conjunto é usado para o treinamento enquanto o restante é usado para teste, e assim sucessivamente até acabar o numero de conjuntos. No caso do 40-fold, a primeira imagem é usada para treino e as demais para teste, e assim sucessivamente. No caso do 20-fold, as duas primeiras imagens são usadas para treino e as demais para teste, e assim sucessivamente. Desse modo, o conjunto de treinamento para os folds 40, 20, 10 e 5 é de respectivamente $2.5 \%, 5 \%, 10 \%$ e $20 \%$ da base toda.

\subsubsection{Seleção de características com aprendizado ativo}

Depois dos testes com MLE e seleção de características por ordenação, foi realizado mais um experimento a fim de melhorar o desempenho da base. Até o momento, o processo era assim: dada uma base de dados, ordena as dimensões por algum dos métodos propostos e seleciona as $p$ primeiras dimensões desse vetor, em que $p$ é o resultado do MLE ao analisar a base de treinamento. O que se propõe agora é usar o aprendizado ativo (AA) para selecionar os exemplos que recaem em uma região de incerteza e então rotulá-los e incorporá-los ao conjunto de treinamento. Após incorporar ao conjunto de treinamento, é calculada novamente a estimativa de dimensões usando o MLE e então o novo vetor de dimensões é ordenado. O novo cálculo do MLE ocorre pois as dimensões intrínsecas podem se alterar com a mudança da base de treinamento.

Nessa etapa, foi utilizada a heurística de Margin Sample que seleciona os exemplos mais próximos à linha de decisão. A região próxima à linha de decisão do classificador também 
é chamada de região de incerteza. O SVM foi adaptado para usar aprendizado ativo, e os exemplos que obtiveram resultados entre 0.45 e 0.55 na distribuição de probabilidade de classes, foram agregados ao conjunto de treinamento com suas verdadeiras classes. Já o algoritmo de GM foi adaptado para que 5\% dos valores que ficarem próximo ao threshold fossem selecionados para o aprendizado ativo. Pelo GM ser um algoritmo de one class, os exemplos da classe positiva foram agregados para no conjunto de treinamento, e os da classe negativa agregados ao conjunto de validação. O valor de $5 \%$ foi proposto de forma empirica, não sendo investigado neste trabalho métodos de ajuste desse limiar. Um outro detalhe é que, para os ensaios computacionais, realizou-se apenas uma iteração no algoritmo de AA.

A seguir é apresentado o Algoritmo 1, que mostra o processo de classificação com a heurística de AA. Nesse algoritmo, as funções classe_verdadeira (...) e classe_predita (...) retornam a classe verdadeira e a classe predita do exemplo fornecido como parâmetro. A heurística usada é a Margin Sample e, caso um exemplo classificado erroneamente pertença a região de incerteza, esse exemplo é então incorporado no conjunto de treinamento e o classificador é retreinado. A variável vetor instancias representa os exemplos preditos. A função score(...) retorna a probabilidade da determinada instância pertencer a uma determinada classe.

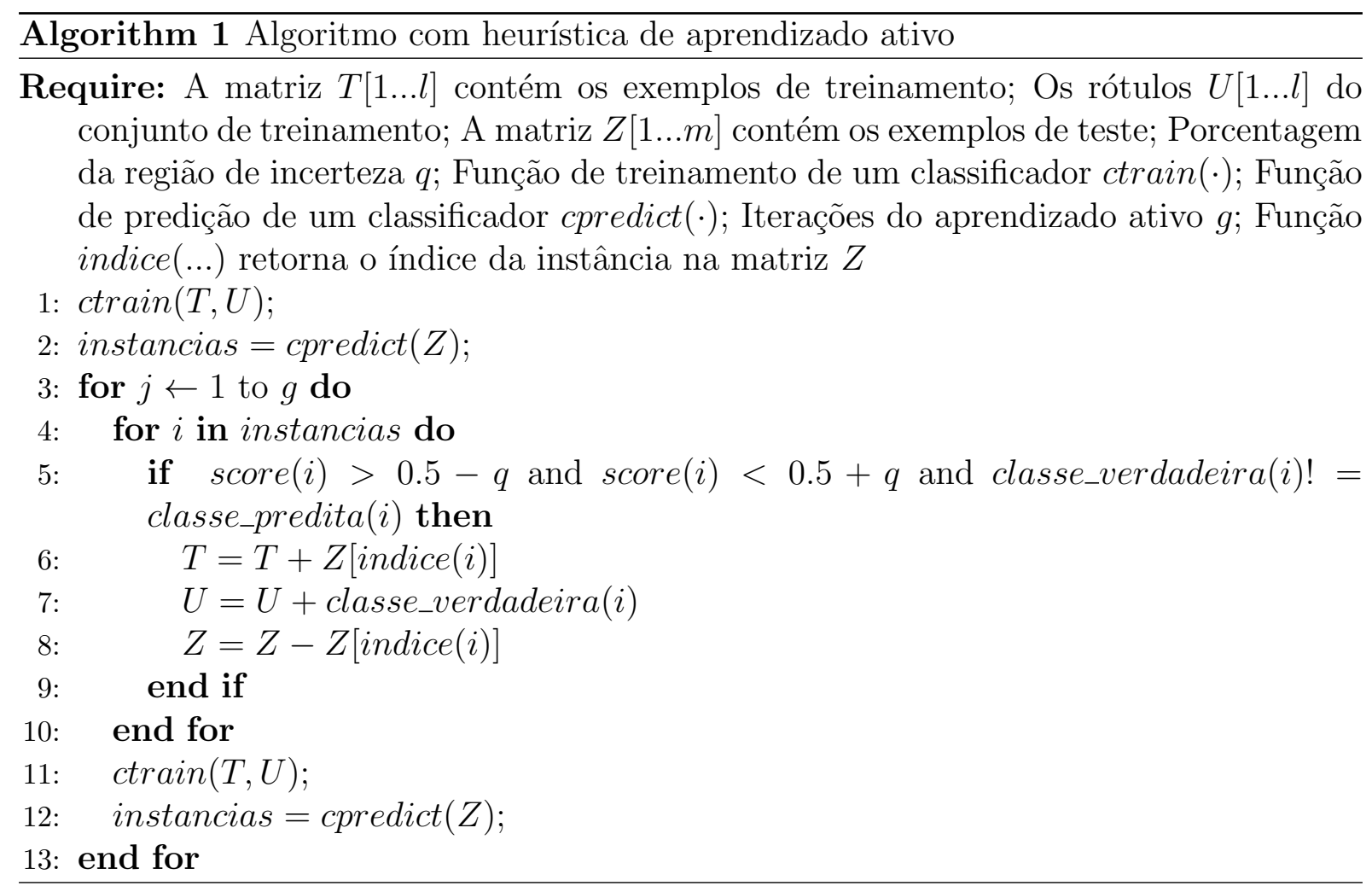


As linhas 1 e 2 do algoritmo executam as etapas de treinamento e predição. O laço na linha 3 é usado para iterar a heurística de AA que, para os ensaios computacionais deste estudo foi utilizado apenas 1 iteração. Na linha 4 existe outro laço responsável por percorrer os exemplos preditos. Em seguida, cada exemplo é verificado se pertence ou não à região de incerteza, como pode ser visto na linha 5. Caso o exemplo pertença à região de incerteza, ele é adicionado ao conjunto de treinamento, recebe seu rótulo verdadeiro por meio da função classe_verdadeira(), e por fim é retirado do conjunto de teste, como mostrado nas linhas 6, 7 e 8. Após todos os exemplos preditos serem analisados, nas linhas 11 e 12 ocorrem novamente as etapas de treinamento e predição porém agora com o novo conjunto de treinamento.

A Figura 4.10 apresenta os principais passos desse processo, aqui chamado de Pipeline 2. O processo é similar ao proposto no Pipeline 1, porém foi adicionado o ciclo do aprendizado ativo (AA). Após o treinamento do classificador, a heurística de AA seleciona os exemplos que trazem maior benefício para o modelo do classificador. O próximo passo é incorporar esses exemplos no conjunto de treinamento e assim retomar o ciclo da etapa de estimar a quantidade de dimensões intrínsecas.

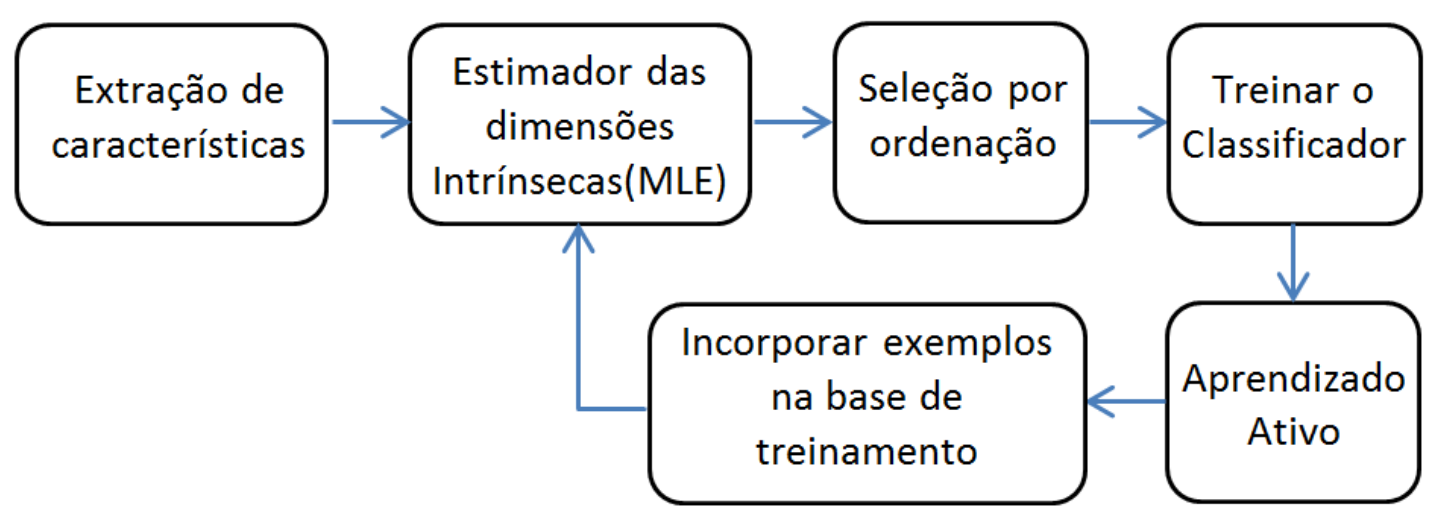

Figura 4.10: Pipeline 2: Adicionada a etapa de aprendizado ativo em relação ao primeiro pipeline.

\subsection{Análise com PCA}

Foi realizada uma etapa de análise dos resultados gerados pelo pipeline 2 (seleção + AA), com os resultados usando o algoritmo PCA. Para essa análise foram usados os $c$ primeiros componentes do PCA, em que $c$ é o valor de corte fornecido pela análise das variâncias das dimensões. 
Para esta análise, a base toda foi usada com o PCA a fim de encontrar a melhor transformação que represente os dados. O PCA foi aplicado assumindo conhecimento completo da base, diferentemente do método proposto que assume conhecimento apenas do conjunto de treinamento. Assim, os resultados obtidos com o PCA representam um limite superior de desempenho para esse método.

\subsection{Considerações Finais}

Este capítulo apresentou as técnicas propostas e os detalhes dos ensaios computacionais. No próximo capítulo serão apresentadas as discussões envolvendo os resultados desses ensaios computacionais. 


\begin{tabular}{l|l} 
Capítulo & 5 \\
5
\end{tabular}

\section{Resultados e Discussões}

\subsection{Considerações Iniciais}

Neste capítulo são apresentados os ensaios computacionais das técnicas detalhadas nos capítulos anteriores. Os testes aqui apresentados fazem uso da base de dados proposta. Na Seção 5.2 são apresentadas as discussões e resultados sobre a análise das características visuais da base de dados. Na Seção 5.3 são apresentadas as discussões dos resultados das técnicas propostas de aprendizado ativo e seleção de características.

\subsection{Análise das características da base de dados}

Os ensaios computacionais desta seção tiveram o objetivo de definir, por meio de um estudo de características visuais, quais as características que melhor descriminam os dados.

Todos os resultados apresentados nesta seção foram executados 10 vezes, e foram obtidos a média e o desvio padrão da acurácia balanceada. O algoritmo de classificação usado foi o OPF.

O experimento 1 buscou identificar quais as características visuais que melhor representam os dados, fixando o descritor para múltiplos índices de vegetação. O extrator de cor BIC obteve o melhor resultado dentre os extratores com uma acurácia média de $90,05 \%$. 
Já o experimento 2 procurou identificar qual o melhor índice de vegetação, fixando o índice e extraindo todas as características. Neste experimento, o índice ExG foi o que obteve o melhor resultado com acurácia média de 89,27\%.

Após definir qual a combinação de índices e de características que melhor discriminam a base, foi realizado então o experimento 3. Esse experimento usou todos os índices e todas as características, ou seja, 328 dimensões. Foram então comparada todas as dimensões com um vetor de características composto pelo melhor índice e melhor característica obtidos nos experimentos anteriores. Esse novo vetor possui 16 dimensões e faz uso do BIC e do ExG.

A Tabela 5.1 apresenta os dados dos experimentos acima citados.

Tabela 5.1: Acurácia média e desvio padrão dos experimentos

\begin{tabular}{llccc}
\hline Experimento & Técnica & Dim. & Acurácia B. & Desvio Padrão \\
\hline \hline \multirow{2}{*}{1} & BIC & 48 & $\mathbf{9 0 , 0 5}$ & 0,212 \\
& HoG & 54 & 76,77 & 0,140 \\
& Haralick & 144 & 86,98 & 0,188 \\
\hline \multirow{2}{*}{2} & CIVE & 82 & 84,67 & 0,175 \\
& ExG & 82 & $\mathbf{8 9 , 2 7}$ & 0,249 \\
3 & VVI & 82 & 80,10 & 0,232 \\
\hline & BIC com ExG & 16 & 89,07 & 0,162 \\
& Todas as características & 328 & $\mathbf{9 0 , 0 1}$ & 0,139 \\
\hline
\end{tabular}

O experimento 1 mostrou que, dentre os extratores de característica, a característica de cor com 48 dimensões foi a que teve o melhor desempenho. No teste 2, ficou evidente que o ExG com 82 dimensões obteve o melhor resultado entre os índices usados. O experimento número 3 mostrou acurácia comparável em usar todas as características e usar apenas BIC com ExG. Porém, é importante ressaltar que o BIC com ExG possui apenas 16 dimensões, enquanto a base total possui 328 dimensões, sendo preferível o uso de vetores com menor dimensão.

Acredita-se em algumas razões para que o resultado dessa análise não seja superior a 90\%, tais como:

1. O algoritmo de classificação usado não foi suficiente para separar os dados das diferentes classes.

2. Como apresentado na Figura 5.1, existem regiões da imagem que possuem vegetação similar à da plantação, porém não foram rotuladas com a classe de cobertura 
vegetal. Ou seja, existe confusão de elementos visualmente similares porém de classes distintas. Adicionar esse tipo de exemplo no conjunto de treinamento, pode resultar em uma redução do desempenho dos algoritmos de AM.

3. São necessárias mais informações como o infra-vermelho próximo. É conhecido na área de sensoriamento remoto que, para a representação de vegetação é importante a informação do infravermelho próximo (Carlson e Ripley, 1997). Porém, dado o objetivo de baixo custo que este projeto aborda, foi deixado de obter essa informação.

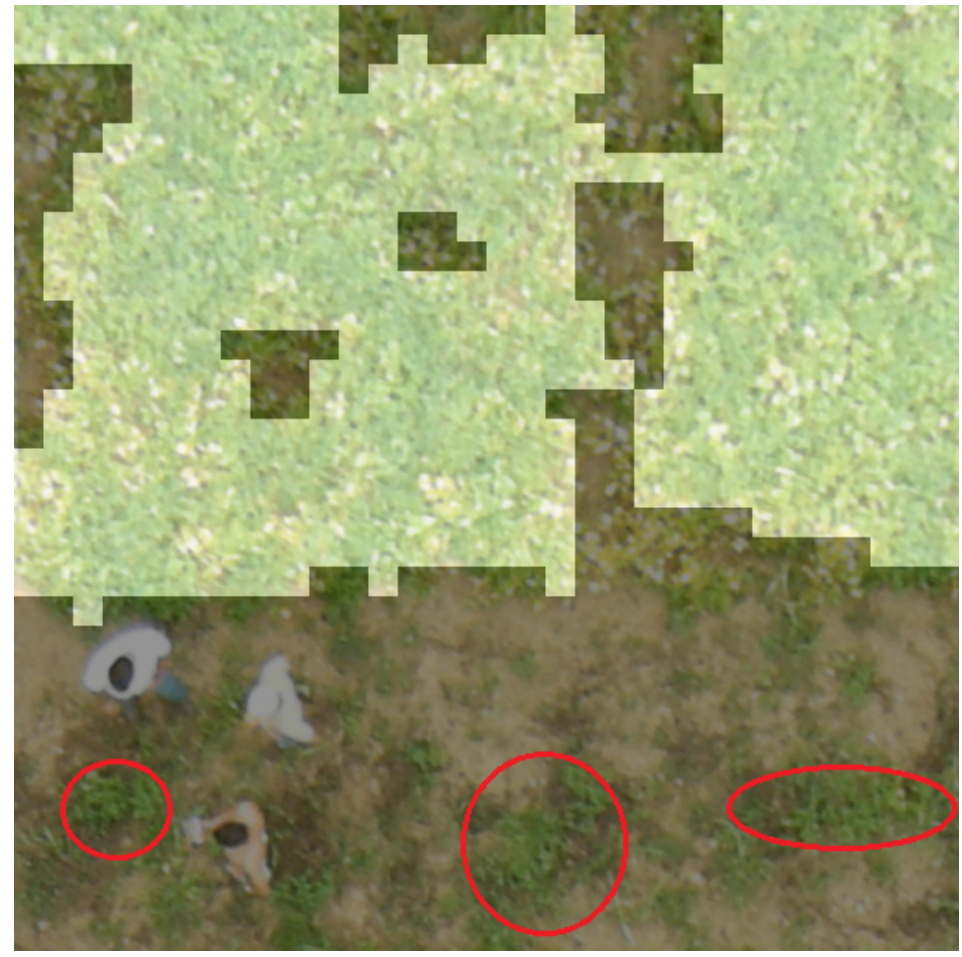

Figura 5.1: Exemplo de imagem da base de dados que possui classes rotuladas erradas. A região circulada mostra vegetações similares a da plantação. As regiões claras são de cobertura vegetal e as escuras da classe oposta.

\subsection{Seleção de características por ordenação}

Nesta seção são apresentados os ensaios computacionais para se definir um pipeline que permita trabalhar com bases desbalanceadas de forma automática.

\subsubsection{Seleção por ordenação}

Para se definir qual das três técnicas de ordenação melhor beneficiam o treinamento do modelo, foram realizados alguns ensaios computacionais. Primeiramente, toda a base de 
dados foi analisada, ou seja, os 40960 exemplos foram usados para o cálculo do vetor ordenado de dimensões. O MLE foi usado para calcular a quantidade de dimensões, que para essa base obteve 17 dimensões intrínsecas.

A Tabela 5.2 apresenta as dimensões e as características retornadas por cada técnica de ordenação. A ordem das linhas é a ordem de ordenação de cada técnica. Nessa tabela, o índice VVI é o com parâmetro $w=1$ e o VVI2 é o com parâmetro $w=10$. Na tabela, o Haralick é dividido em 8 tipos, cada um representando um ângulo diferente, e o valor entre os colchetes indica o extrator de Haralick usado. Os valores dentro dos colchetes do BIC e do HOG representam qual a posição do histograma àquela dimensão pertence.

Tabela 5.2: Dimensões ordenadas de acordo com cada técnica de ordenação sendo mais importante a característica mais alta no ranking. São apresentadas as 17 primeiras dimensões de cada técnica. A técnica 1 é a ordenação pela maior variância; a técnica 2 é a ordenação pela menor soma das variâncias de cada classe; a técnica 3 é a ordenação pela maior diferença das médias das classes.

\begin{tabular}{c|rl|rl|rl}
\hline Rank & \multicolumn{3}{|c}{ Técnica 1 } & \multicolumn{2}{c}{ Técnica 2 } & \multicolumn{1}{c}{ Técnica 3 } \\
\hline 01 & 172 & VVI-BIC[8] & 165 & VVI-BIC[1] & 2 & EXG-BIC[2] \\
02 & 171 & VVI-BIC[7] & 88 & CIVE-BIC[6] & 88 & CIVE-BIC[6] \\
03 & 180 & VVI-BIC[16] & 203 & VVI-Haralick1[5] & 165 & VVI-BIC[1] \\
04 & 254 & VVI2-BIC[8] & 209 & VVI-Haralick2[5] & 85 & CIVE-BIC[3] \\
05 & 170 & VVI-BIC[6] & 185 & VVI-HOG[5] & 203 & VVI-Haralick1[5] \\
06 & 90 & CIVE-BIC[8] & 227 & VVI-Haralick5[5] & 209 & VVI-Haralick2[5] \\
07 & 83 & CIVE-BIC[1] & 191 & VVI-HOG[11] & 249 & VVI2-BIC[3] \\
08 & 7 & ExG-BIC[7] & 221 & VVI-Haralick4[5] & 12 & EXG-BIC[12] \\
09 & 179 & VVI-BIC[15] & 204 & VVI-Haralick1[6] & 39 & EXG-Haralick1[5] \\
10 & 262 & VVI2-BIC[16] & 210 & VVI-Haralick4[6] & 45 & EXG-Haralick2[5] \\
11 & 91 & CIVE-BIC[9] & 197 & VVI-HOG[17] & 191 & VVI-HOG[11] \\
12 & 98 & CIVE-BIC[16] & 215 & VVI-Haralick3[5] & 221 & VVI-Haralick4[5] \\
13 & 169 & VVI-BIC[5] & 192 & VVI-HOG[12] & 185 & VVI-HOG[5] \\
14 & 178 & VVI-BIC[14] & 222 & VVI-Haralick4[6] & 227 & VVI-Haralick5[5] \\
15 & 6 & ExG-BIC[6] & 186 & VVI-HOG[6] & 197 & VVI-HOG[17] \\
16 & 255 & VVI2-BIC[9] & 228 & VVI-Haralick5[5] & 215 & VVI-Haralick3[5] \\
17 & 20 & ExG-HOG[4] & 198 & VVI-HOG[18] & 27 & EXG-HOG[11] \\
\hline
\end{tabular}

Ao analisar as dimensões geradas pela técnica 1, observa-se que a característica de cor predomina. Também é observado que os índices VVI e VVI2 são predominantes. A técnica 2 possui predominância do índice de vegetação VVI, e as características usadas foram orientação e textura, essa última com o Haralick5 que representa a Homogeneidade e o Haralick6 que representa a Entropia. A técnica 3 por sua vez não possui uma predominância de um índice de vegetação e nem de uma característica específica. O 
que se pode observar dessa técnica é que as dimensões mais significativas, e que aparecem no começo do vetor ordenado, são características de cor, enquanto as características menos significativas posicionadas ao final do vetor, possui características de textura (Homogeneidade) e orientação.

Após essa analise das dimensões, e já com o número estimado de dimensões intrínsecas e os vetores ordenados, foram realizados alguns testes com o SVM para identificar qual das três técnicas fornecem o melhor resultado. Foi usado o K-fold cross validation para se avaliar qual a melhor técnica de seleção. Para o algoritmo SVM foram usados os Kernels polinomial e radial, com os demais parâmetros do algoritmo obtidos por meio de uma busca em grid. Para esse ensaio computacional, a técnica de seleção por variância independente de classe, a de variância dependendo da classe, e a da diferença das médias, são nomeadas de experimento 1, 2 e 3 respectivamente. Os resultados dessa análise são apresentados na Tabela 5.3 para o teste que usou o Kernel Polinomial, e na Tabela 5.4 o resultado do Kernel Radial.

Um detalhe dos testes desta seção é o uso das imagens 1 e 15 da base, durante o teste de 40 do K-fold cross validation. Essas imagens possuem os 1024 exemplos pertencentes à classe de cobertura vegetal, e nenhum exemplo da outra classe. Por esse motivo, essas imagens não podem ser usadas para treinamento do classificador, e os testes envolvendo-as foram ignorados.

Tabela 5.3: Resultado dos testes usando o Kernel Polinomial e o algoritmo SVM.

\begin{tabular}{clcc}
\hline Técnica & Folds & Acurácia Média & Desvio Padrão \\
\hline \hline \multirow{4}{*}{1} & 40 & 0,7385 & 0,1018 \\
& 20 & 0,7540 & 0,0926 \\
& 10 & 0,7584 & 0,0824 \\
& 05 & 0,7853 & 0,0639 \\
\hline \multirow{4}{*}{2} & 40 & 0,5 & 0 \\
& 20 & 0,5 & 0 \\
& 10 & 0,5 & 0 \\
3 & 05 & 0,5 & 0 \\
\hline \multirow{3}{*}{3} & 40 & $\mathbf{0 , 8 2 2 0}$ & 0,0884 \\
& 20 & $\mathbf{0 , 8 3 7 0}$ & 0,0815 \\
& 10 & $\mathbf{0 , 8 5 1 3}$ & 0,0534 \\
& 05 & $\mathbf{0 , 8 5 1 6}$ & 0,0412 \\
\hline
\end{tabular}

De um modo geral, a técnica 3 que ordena pela diferença da média, obteve melhores resultados comparado com as outras ordenações. A técnica 2 apresentou resultados 
Tabela 5.4: Resultado dos testes usando o Kernel Radial e o algoritmo SVM.

\begin{tabular}{clcc}
\hline Técnica & Folds & Acurácia Média & Desvio Padrão \\
\hline \hline \multirow{3}{*}{1} & 40 & 0,7657 & 0,1203 \\
& 20 & 0,7691 & 0,0926 \\
& 10 & 0,8010 & 0,1182 \\
& 05 & 0,8228 & 0,0769 \\
\hline \multirow{4}{*}{2} & 40 & 0,5 & 0 \\
& 20 & 0,5 & 0 \\
& 10 & 0,5 & 0 \\
3 & 05 & 0,5 & 0 \\
\hline \multirow{3}{*}{3} & 40 & $\mathbf{0 , 8 2 3 4}$ & 0,1351 \\
& 20 & $\mathbf{0 , 8 3 1 0}$ & 0,1391 \\
& 10 & $\mathbf{0 , 8 6 0 6}$ & 0,1150 \\
& 05 & $\mathbf{0 , 8 9 7 0}$ & 0,0206 \\
\hline
\end{tabular}

ruins similares a um classificador aleatório, indicando não ser uma boa ordenação para o classificador SVM.

A seguir, na Tabela 5.5 são apresentados os resultados do $K$-fold cross validation obtidos usando o algoritmo GM. Para as imagens 1 e 15 foi usado o Threshold fixo de 0.01, pois como comentado, essas imagens não possuem classes negativas, e por isso, não é possível calcular o Threshold na etapa de validação.

Tabela 5.5: Resultado dos testes usando o algoritmo GM.

\begin{tabular}{clcc}
\hline Técnica & Folds & Acurácia Média & Desvio Padrão \\
\hline \hline \multirow{4}{*}{1} & 40 & $\mathbf{0 , 6 8 4 6}$ & 0,0536 \\
& 20 & $\mathbf{0 , 7 2 4 8}$ & 0,0600 \\
& 10 & $\mathbf{0 , 7 5 3 5}$ & 0,0391 \\
& 05 & $\mathbf{0 , 7 7 5 2}$ & 0,0211 \\
\hline \multirow{3}{*}{2} & 40 & 0,5798 & 0,0994 \\
& 20 & 0,6021 & 0,0920 \\
& 10 & 0,6014 & 0,0683 \\
3 & 05 & 0,5758 & 0,0859 \\
\hline \multirow{3}{*}{3} & 40 & 0,6381 & 0,0495 \\
& 20 & 0,7001 & 0,0627 \\
& 10 & 0,7380 & 0,0620 \\
& 05 & 0,7710 & 0,0492 \\
\hline
\end{tabular}


Nos testes envolvendo o algoritmo GM, a técnica que obteve o melhor resultado foi a técnica 1, seguida pela técnica 3 e por último a técnica 2. Outra observação é que a abordagem One-Class do algoritmo GM apresentou um desempenho inferior ao algoritmo SVM. Um motivo para esse baixo desempenho talvez tenha sido a própria distribuição dos dados, e que não pode ser bem representada por uma distribuição gaussiana.

\subsubsection{Pipeline 1}

Os testes anteriores usaram tanto a quantidade de dimensões, de valor 17, quanto a ordenação delas de forma fixa, independente do conjunto de treinamento. Ou seja, Foram usados valores calculados de toda a base de dados e não apenas do conjunto de treinamento.

Os próximos testes apresentam o pipeline proposto, que incluem o cálculo do MLE e a criação dos vetores ordenados de acordo com a base de treinamento. Também foi definido que a técnica de ordenação que trouxe melhor desempenho para os modelos foi a técnica 3 que usa a diferença da média entre as classes. Os resultados dos algoritmos SVM e GM podem ser vistos na Tabela 5.6. Dentre as técnicas utilizadas, o SVM com o Kernel radial foi o que apresentou o melhor desempenho em todas as execuções. O algoritmo GM, por ter modelado apenas o conhecimento da classe positiva (cobertura vegetal) obteve desempenho inferior indicando a dificuldade em lidar com dados desbalanceados e pouco conhecimento da classe negativa.

Tabela 5.6: Resultado dos testes dos algoritmos SVM e GM com as dimensões calculadas com o conjunto de treinamento, de acordo com o pipeline proposto.

\begin{tabular}{llcc}
\hline Algoritmo & Folds & Acurácia Média & Desvio Padrão \\
\hline \hline \multirow{4}{*}{ SVM Polinomial } & 40 & 0,7427 & 0,1277 \\
& 20 & $\mathbf{0 , 8 1 8 9}$ & 0,0885 \\
& 10 & 0,8167 & 0,1181 \\
& 05 & 0,8521 & 0,0550 \\
\hline \multirow{3}{*}{ SVM Radial } & 40 & $\mathbf{0 , 8 0 0 2}$ & 0,1184 \\
& 20 & $\mathbf{0 , 8 1 8 5}$ & 0,1191 \\
& 10 & $\mathbf{0 , 8 4 3 0}$ & 0,1162 \\
\multirow{4}{*}{ GM } & 05 & $\mathbf{0 , 8 9 8 0}$ & 0,0275 \\
& 40 & 0,6501 & 0,1184 \\
& 20 & 0,6999 & 0,0916 \\
& 10 & 0,7415 & 0,0782 \\
& 05 & 0,7615 & 0,0705 \\
\hline
\end{tabular}




\subsubsection{Pipeline 2 - Adicionando Aprendizado Ativo}

Após os resultados com o pipeline 1, foi proposto usar heurísticas de aprendizado ativo, e assim esse processo foi chamado de pipeline 2. A heurística de AA tem o objetivo de selecionar os exemplos mais indecisos quanto à classe predita e, em seguida, classificar com seu rótulo verdadeiro. O rótulo pode ser confirmado e assim ele não se altera, ou ele pode trocar de classe já que foi predito incorretamente. Apenas os exemplos que seus rótulos foram alterados são incorporados no conjunto de treinamento. Esses exemplos geralmente são identificados como Falso Positivo (FP) e Falso Negativo (FN). Os FP são exemplos preditos como de cobertura vegetal porém sua classe verdadeira é a negativa. Já os FN são preditos como negativos, porém sua classe verdadeira é a de cobertura vegetal. A Figura 5.2 exemplifica uma classificação usando $\mathrm{OPF}$ das sub-imagens de $16 \times 16$. Além do FP e FN, essa figura também mostra o Verdadeiro Negativo (VN) e o Verdadeiro Positivo (VP). Um destaque nessa figura é a semelhança visual entre as classificações FP e FN, que são os exemplos com maiores probabilidades de serem selecionados pelo AA.

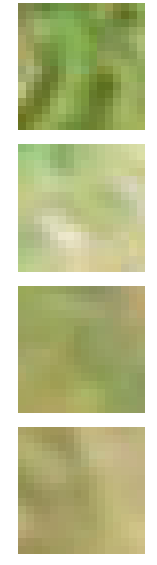

$(\mathrm{VN})$

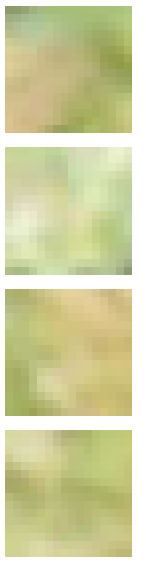

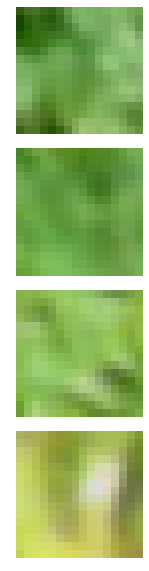

$(\mathrm{FP})$

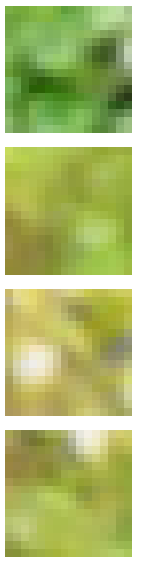

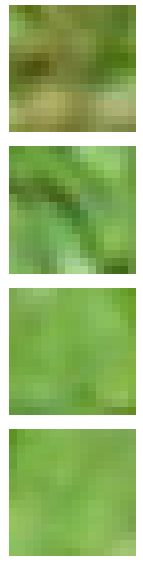

$(\mathrm{FN})$
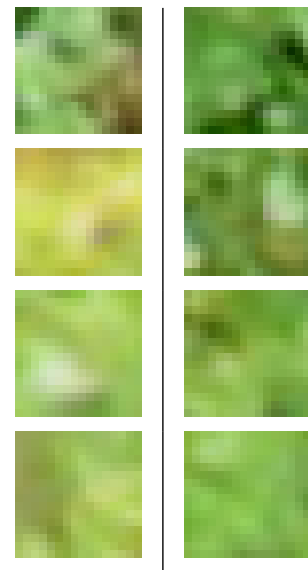

$(\mathrm{VP})$
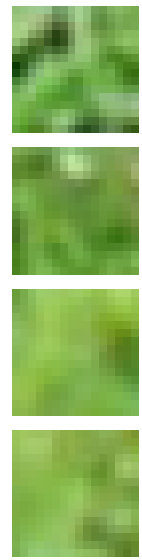

Figura 5.2

Os algoritmos SVM e GM foram adaptados para usarem a heurística de AA e, em seguida, foram comparados. Na Tabela 5.7, é apresentado o comparativo entre o SVM de Kernel Radial com e sem a heurística de aprendizado ativo, e o algoritmo GM com e sem AA. Embora o algoritmo GM não tenha obtido um bom desempenho em testes anteriores, foi decidido continuar com esse algoritmo por causa de sua abordagem one-class.

A Tabela 5.8 apresenta a média e desvio padrão da quantidade de exemplos retornados pelo AA. Vale lembrar que o AA apenas usou uma iteração.

A técnica utilizando a heurística de AA, apresentou uma melhora do desempenho de modo geral, principalmente no 40-folds em que o desempenho melhorou cerca de $7 \%$ e o 
Tabela 5.7: Resultado dos testes de acordo com o Pipeline 2. Foi utilizado o algoritmo SVM com kernel Radial com e sem aprendizado ativo.

\begin{tabular}{llcc}
\hline Algoritmo & Folds & Acurácia Média & Desvio Padrão \\
\hline \hline \multirow{3}{*}{ SVM sem AA } & 40 & 0,8002 & 0,1184 \\
& 20 & 0,8185 & 0,1191 \\
& 10 & 0,8430 & 0,1162 \\
& 05 & 0,8980 & 0,0275 \\
\hline \multirow{3}{*}{ SVM com AA } & 40 & $\mathbf{0 , 8 7 6 3}$ & 0,0803 \\
& 20 & $\mathbf{0 , 8 8 1 3}$ & 0,0590 \\
& 10 & $\mathbf{0 , 8 7 8 0}$ & 0,0651 \\
GM sem AA & 05 & $\mathbf{0 , 9 0 7 1}$ & 0,0210 \\
\hline & 40 & 0,6501 & 0,1184 \\
& 10 & 0,6999 & 0,0916 \\
GM com AA & 05 & 0,7415 & 0,0782 \\
& 40 & 0,7615 & 0,0705 \\
\hline & 10 & 0,6789 & 0,0961 \\
& 05 & 0,7237 & 0,1048 \\
& & 0,7566 & 0,0765 \\
& & & 0,0715 \\
\hline
\end{tabular}

Tabela 5.8: Quantidade de exemplos selecionados pela heurística de aprendizado ativo em cada um dos folds. No fold 40, os exemplos 1 e 15 foram ignorados por não possuírem exemplos da classe negativa.

\begin{tabular}{lcccc}
\hline Folds & Média & Desvio Padrão & Max & Min \\
\hline 40 & 939,74 & 1227,68 & 7587 & 23 \\
20 & 838,53 & 1127,96 & 5602 & 180 \\
10 & 321,50 & 123,53 & 529 & 156 \\
05 & 264,40 & 102,24 & 400 & 126 \\
\hline
\end{tabular}


desvio padrão que diminuiu em cerca de 4\%, em comparação com a técnica sem o AA. Para o experimento 40-folds, o qual possuia um conjunto de treinamento inicial de 1024 exemplos (2,5\% da base), uma média de 939 exemplos foram selecionados pelo AA. Por tanto, após essa etapa, o conjunto de treinamento possui em média $1024+939=1963$ exemplos, o que representa aproximadamente $4,8 \%$ de toda a base. Com isso, obteve uma acurácia balanceada de 87,63\%, comparável com a acurácia obtida ao usar 8192 exemplos ( $25 \%$ da base) para o treinamento no algoritmo SVM sem o AA, relativo ao experimento 5 -folds.

\subsubsection{Análise com PCA}

Foi realizada uma análise dos resultados do PCA com o da técnica proposta. O PCA foi usado na base toda, e não em cada fold, para assim obter a melhor transformação dos dados. A Figura 5.3 apresenta a variância das 10 primeiras dimensões do PCA em um total de 328 dimensões. É notado que, após o sétimo componente principal, a diferença da variância do componente anterior para o próximo se estabiliza, e por esse motivo foi usado apenas os 7 primeiros componentes.

A Figura 5.4 apresenta o gráfico dos dois primeiros componentes principais da base gerada pelo PCA. É observada uma certa separação dos dados com predominância dos exemplos da classe de cobertura vegetal em azul à esquerda, e da classe negativa em vermelha à direita. Já a Figura 5.5 apresenta a projeção das duas melhores dimensões retornadas pela técnica 3 de seleção pela diferença da média, como mostrado na Tabela 5.2 .

Os gráficos tanto do PCA quanto das duas primeiras dimensões da técnica proposta, apresentaram dados consideravelmente separados. É possível identificar visualmente que as duas primeiras dimensões das duas técnicas trazem ótimos benefícios para o treinamento do classificador.

A Tabela 5.9 apresenta os resultados dos testes envolvendo o PCA e o SVM com os kernels Radial, Polinomial e Linear. Esses três são comparados com o SVM Radial + AA originário do pipeline 2.

Os resultados mostram que o PCA+SVM Linear apresentou desempenho semelhante ao SVM Radial com AA proposto pelo pipeline 2. É importante ressaltar que a transformação do PCA foi referente à base toda, ou seja, toda a base foi analisada para se obter a melhor transformação, e não apenas o subconjunto de treinamento de cada fold.

Com esses resultados, é possível identificar que tanto a sequência de processos apresentados pelo pipeline 2 quanto o PCA+SVM Linear melhoraram os resultados quando 


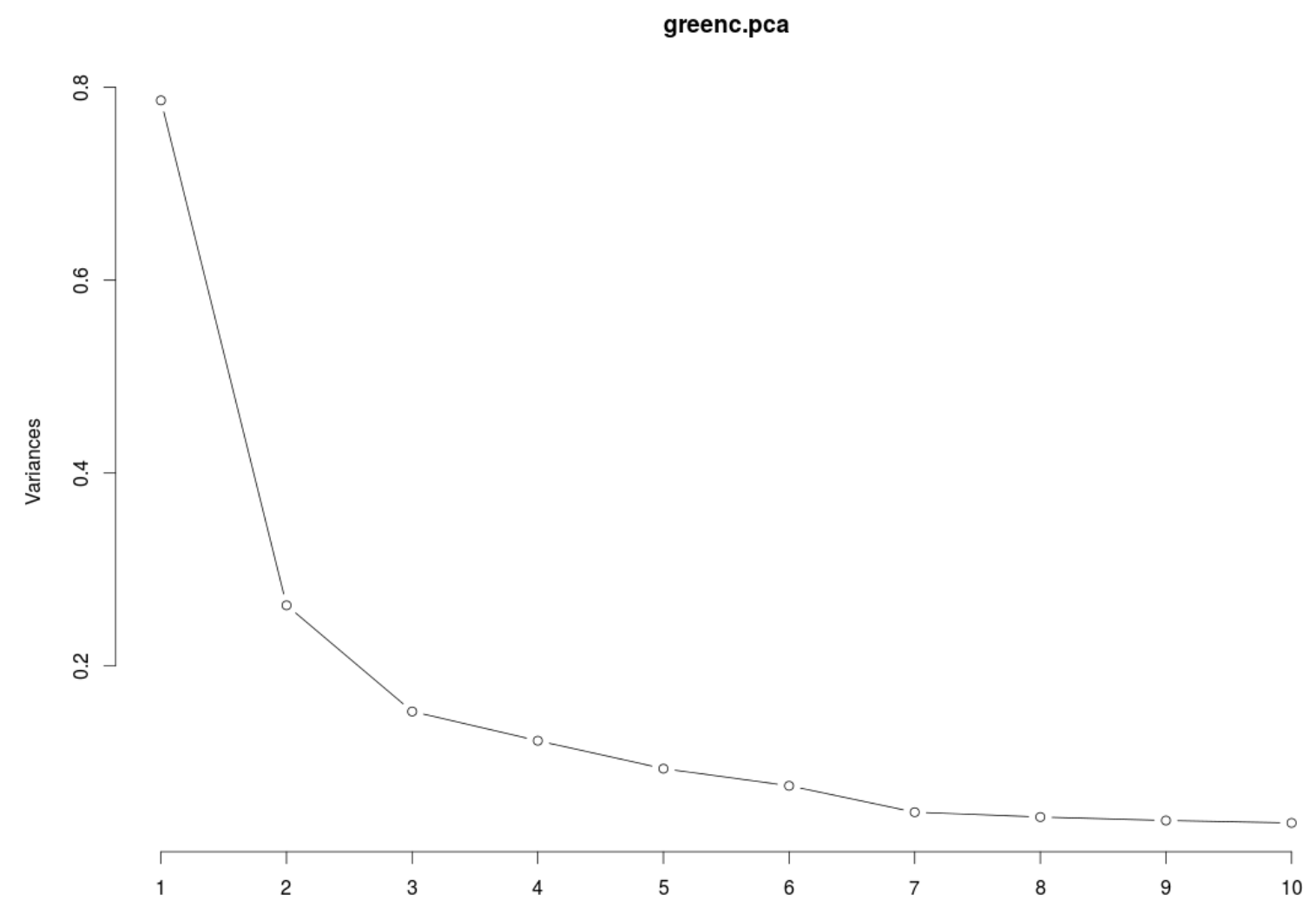

Figura 5.3: Imagem apresentando a variância das dimensões do PCA. São apresentadas as 10 primeiras dimensões de 328 . 


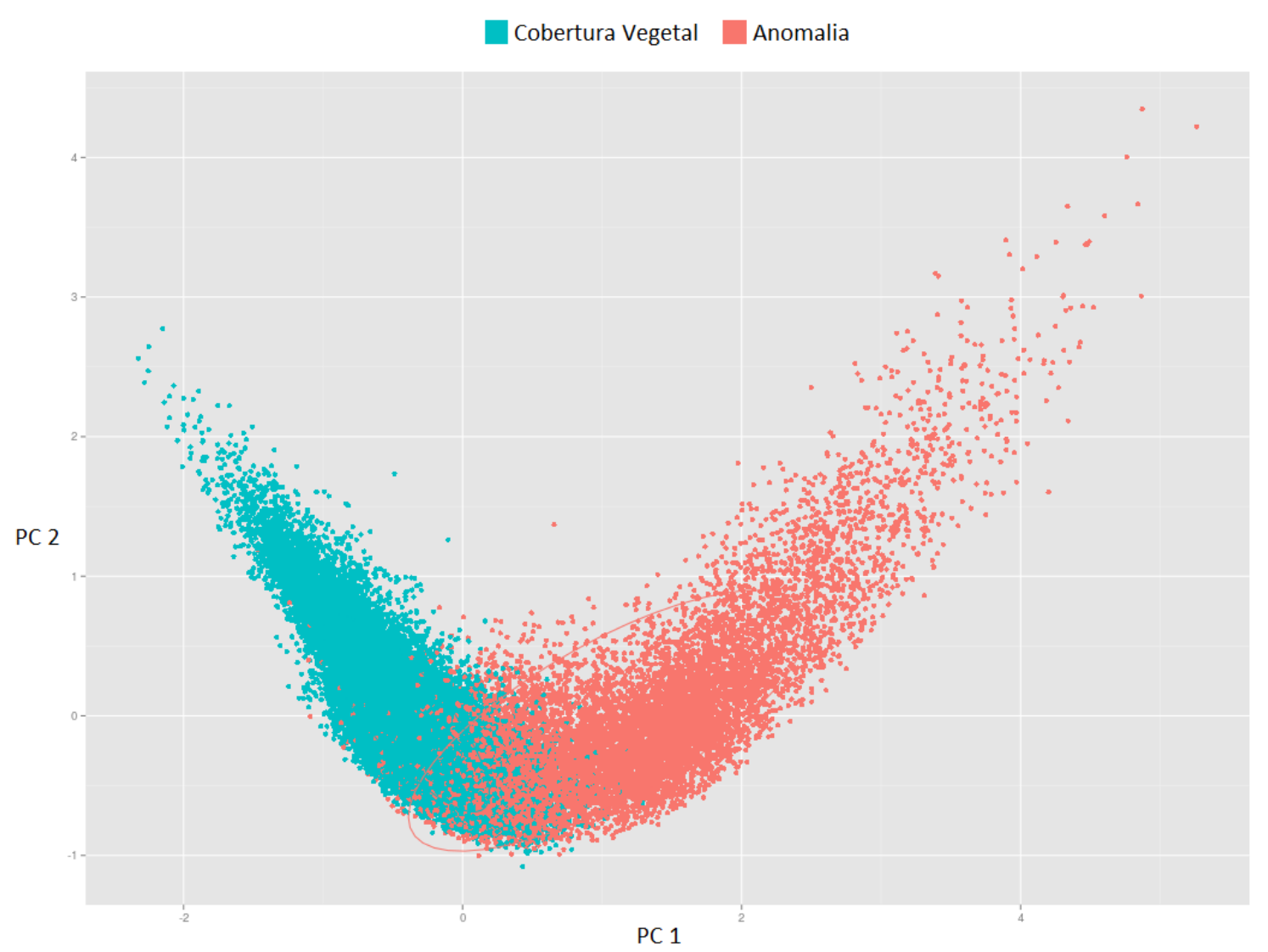

Figura 5.4: Projeção dos dois primeiros componentes principais do PCA 


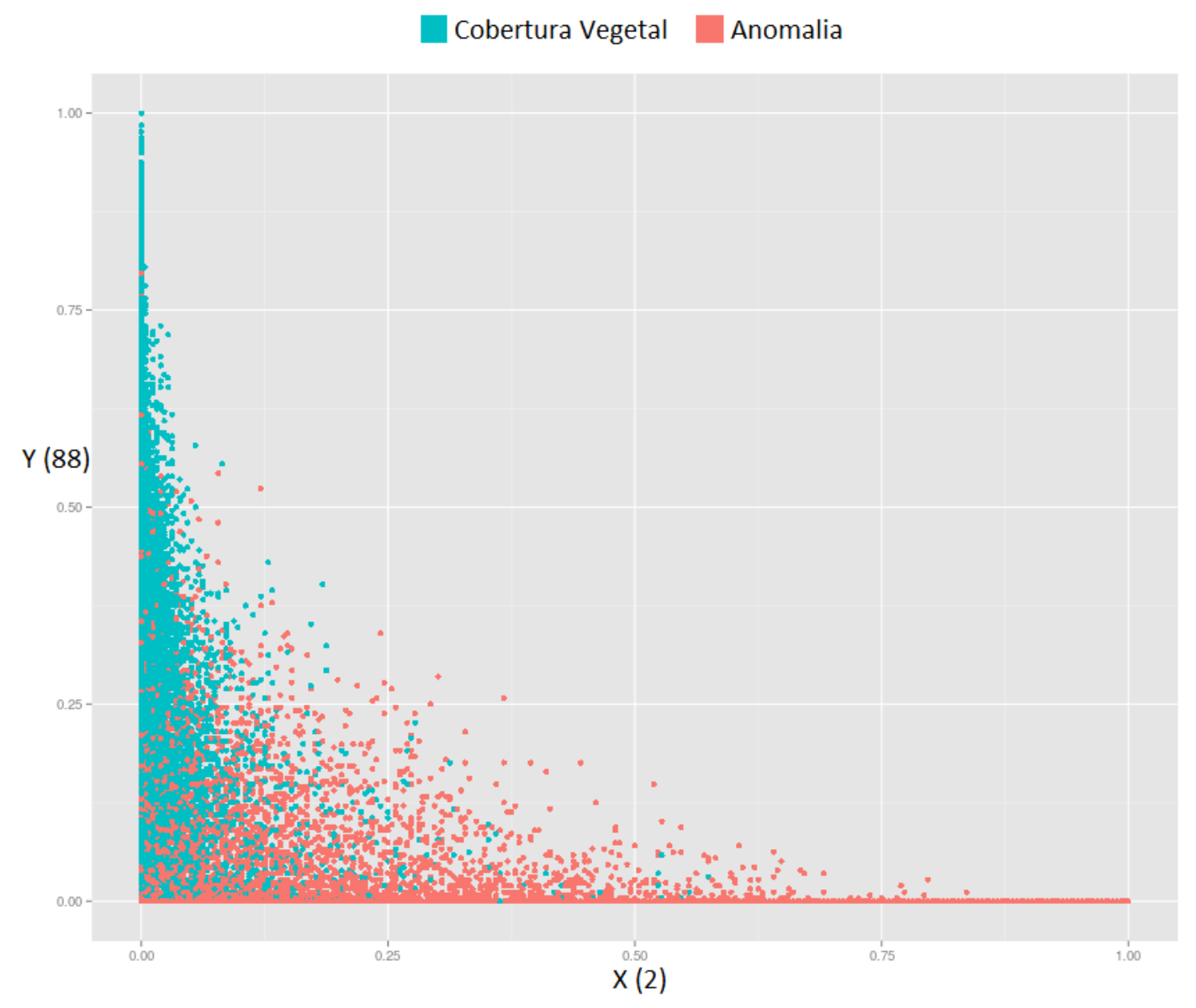

Figura 5.5: Projeção das duas primeiras dimensões fornecidas pela ordenação da diferença das médias como apresentado na Tabela 5.2. 
Tabela 5.9: Resultado dos testes de acordo com o Pipeline 2. Foi utilizado o algoritmo SVM com kernel Radial com e sem aprendizado ativo.

\begin{tabular}{llcc}
\hline Algoritmo & Folds & Acurácia Média & Desvio Padrão \\
\hline \hline \multirow{4}{*}{ SVM Radial com AA } & 40 & $\mathbf{0 , 8 7 6 3}$ & 0,0803 \\
& 20 & $\mathbf{0 , 8 8 1 3}$ & 0,0590 \\
& 10 & $\mathbf{0 , 8 7 8 0}$ & 0,0651 \\
& 05 & $\mathbf{0 , 9 0 7 1}$ & 0,0210 \\
\hline \multirow{5}{*}{ PCA+SVM Polinomial } & 40 & 0,7868 & 0,0816 \\
& 20 & 0,8153 & 0,0555 \\
& 10 & 0,8547 & 0,0385 \\
PCA+SVM Radial & 05 & 0,8725 & 0,0220 \\
\hline & 40 & 0,7236 & 0,1011 \\
PCA+SVM Linear & 20 & 0,7542 & 0,1087 \\
& 10 & 0,8218 & 0,1010 \\
& 05 & 0,8505 & 0,0483 \\
\hline & 40 & $\mathbf{0 , 8 5 9 6}$ & 0,0703 \\
& 10 & $\mathbf{0 , 8 5 2 2}$ & 0,0918 \\
& 05 & $\mathbf{0 , 8 7 8 4}$ & 0,0358 \\
& & $\mathbf{0 , 8 9 5 6}$ & 0,0179 \\
\hline
\end{tabular}

comparados ao uso da base original. Também é importante ressaltar que o ponto negativo das técnicas propostas é o tempo computacional gasto pelo algoritmo MLE, que aumentam proporcionalmente à quantidade de exemplos, à quantidade de vizinhos e às dimensões a serem analisadas.

\subsection{Considerações Finais}

Neste capítulo foram apresentados os resultados e as discussões sobre os experimentos executados. Os estudos desta seção mostraram que técnicas de seleção de características e aprendizado ativo são capazes de melhorar o modelo. O aprendizado ativo, além de ter conseguido aumentar a acurácia balanceada, também conseguiu reduzir o desvio padrão, principalmente nos testes com poucas exemplos de treinamento. No próximo capítulo serão apresentadas as conclusões e os trabalhos futuros. 


\section{Conclusões}

\subsection{Conclusões}

Neste trabalho foi apresentada a análise de uma base de imagens de sensoriamento remoto de baixa altitude, com aplicação na detecção de cobertura vegetal. Foram realizados diversos estudos utilizando essa base para identificar quais as características que melhor representam a base de dados. Para isso foi proposto utilizar os descritores de cor BIC, de gradiente orientado HOG, e de textura Haralick. Além disso foi proposta a utilização de índices de vegetações com o objetivo de melhor separar o que é vegetação do que não é. Os índices de vegetação usados foram o ExG, CIVE e VVI. Após a extração de todas as características e de todos os índices, foi identificado que o índice ExG com o extrator de cor BIC é a combinação de características que melhor representam as classes da base de dados.

Em uma segunda etapa foi proposta a criação de dois pipelines para se identificar as melhores características. Dentre as três técnicas de seleção de características estudadas, a que obteve o melhor resultado foi a seleção por diferença das médias de cada classe, onde o vetor de dimensão foi ordenado de forma decrescente. No pipeline 2, a heurística de aprendizado ativo apresentou-se como uma alternativa viável aumentando em até $7 \%$ a acurácia balanceada e diminuindo em cerca de $4 \%$ o desvio padrão, ao se comparar com técnicas tradicionais. Observou-se que o maior ganho de desempenho entre a técnica proposta e as técnicas tradicionais ocorrem quando existe um alto grau de desbalanceamento 
e existem poucos exemplos para treino.Conclui-se também que as técnicas propostas se demonstraram promissoras já que possuem resultados similares à técnicas como PCA no aspecto de acurácia de classificação.

\subsection{Limitações}

Uma das limitações identificadas neste trabalho, envolve o tempo de processamento do estimador da quantidade de dimensões intrínsecas, o algoritmo MLE. A quantidade de exemplos e de dimensões contidas na base de dados são fatores diretamente envolvidos ao elevado tempo de processamento da técnica. Outro fator é o valor da variável $K$ que representa os vizinhos a serem analisados pelo algoritmo MLE que, quanto mais vizinhos, maior o tempo de processamento.

A aplicação do PCA foi realizada em todo o conjunto de dados antes da divisão em conjuntos de treinamento e teste. Apesar desse experimento fornecer informações importantes para a análise dos dados, esse protocolo não é realistico sendo necessários estudos futuros para testar a robustez desse método em cenários reais.

Outra limitação é a falta de informações de contexto referente a posição dos exemplos. Informações dos vizinhos de cada exemplo poderiam ser úteis no momento da classificação, pois caso o exemplo a ser classificado estiver rodeado por vizinhos já classificados como pertencente à classe positiva, a probabilidade deste exemplo de também pertencer à classe positiva é alta.

As imagens da base de dados pertencem a duas plantações distintas, o que pôde ter influenciado no desempenho dos classificadores. A primeira plantação possui folhagem mais verde enquanto na segunda plantação, a folhagem é amarelada. Métodos de aprendizagem transdutiva podem ser usados nesse contexto.

\subsection{Trabalhos Futuros}

Os trabalhos futuros identificados são listados abaixo:

1. Estudar novas heurísticas de aprendizado ativo, e estudar melhor os limiares de seleção de exemplos.

2. Encontrar alternativas para o algoritmo MLE.

3. Buscar soluções em Transfer Learning.

4. Extratores de características que levam em consideração informações de contexto. 


\subsection{Agradecimentos}

Ao Prof. Luciano Vieira e Frederico Martins pela aquisição da base de imagens, e ao Prof. Carlos Eduardo Magalhães e Prof. Cláudio Pagoto pela rotulação das imagens. 


\section{Referências Bibliográficas}

Abramson, Y.; Freund, Y. Active learning for visual object recognition. Relatório Técnico, Technical report, UCSD, 2004.

Alajlan, N.; Pasolli, E.; Melgani, F.; Franzoso, A. Large-scale image classification using active learning. Geoscience and Remote Sensing Letters, IEEE, v. 11, n. 1, p. 259-263, 2014.

Almeida, J.; Rocha, A.; Torres, R.; Goldenstein, S. Making colors worth more than a thousand words. In: Proceedings of the 2008 ACM symposium on Applied computing, ACM, 2008, p. 1180-1186.

Barnett, V.; Lewis, T. Outliers in statistical data. John Wiley \& Sons, 1994.

Bellman, R.; Bittner, L. Adaptive control processes. a guided tour. ZAMM - Journal of Applied Mathematics and Mechanics / Zeitschrift fÃijr Angewandte Mathematik und Mechanik, v. 42, n. 7-8, p. 364-365, 1962.

Disponível em http://dx.doi.org/10.1002/zamm.19620420718

Bengio, Y.; Goodfellow, I. J.; Courville, A. Deep learning, book in preparation for MIT Press, 2014.

Disponível em http://www.iro.umontreal.ca/ bengioy/dlbook

Bietti, A. Active learning for object detection on satellite images. 2012.

Burges, C. J. C. A tutorial on support vector machines for pattern recognition. Data Min. Knowl. Discov., v. 2, n. 2, p. 121-167, 1998.

Disponível em http://dx.doi.org/10.1023/A:1009715923555 
Carlson, T. N.; Ripley, D. A. On the relation between ndvi, fractional vegetation cover, and leaf area index. Remote sensing of Environment, v. 62, n. 3, p. 241-252, 1997.

Carter, P.; Johannsen, C.; Robert, P.; Rust, R.; Larson, W.; et Al. Agricultural cropland anomaly classification system for use with remote sensing data. In: Proceedings of the 5th International Conference on Precision Agriculture, Bloomington, Minnesota, USA, 16-19 July, 2000., American Society of Agronomy, 2000, p. $1-4$.

Carter, P. G.; Johannsen, C. J.; Engel, B. A. Recognizing patterns within cropland vegetation: A crop anomaly classification system. Journal of Terrestrial Observation, v. 1, n. 1, p. 5, 2008.

Chandola, V.; Banerjee, A.; Kumar, A. Anomaly detection: a survey. ACM Computing Surveys, v. 41, n. 3, p. 15, 2009.

Costa, G.; Ponti, M.; Frery, A. Partially supervised anomaly detection using a pairwise estimated parameter space. In: 2th Int. Work. on Partially Supervised Learning (PSL 2013) (accepted), 2013.

DAlal, N.; Triggs, B. Histograms of oriented gradients for human detection. In: Proc. 2005 IEEE Conf. Computer Vision and Pattern Recognition (CVPR'05), 2005, p. $886-893$.

DASH, M.; LiU, H. Feature selection for classification. Intelligent data analysis, v. 1, n. 1, p. 131-156, 1997.

Demir, B.; Bruzzone, L. A novel active learning method in relevance feedback for content-based remote sensing image retrieval. Geoscience and Remote Sensing, IEEE Transactions on, v. 53, n. 5, p. 2323-2334, 2015.

Domingos, P. A few useful things to know about machine learning. Commun. ACM, v. 55, n. 10, p. 78-87, 2012.

Disponível em http://doi.acm.org/10.1145/2347736.2347755

Faceli, K.; Lorena, A. C.; Gama, J. M. P.; Carvalho, A. C. P. L. F. InteligÃtncia artificial - uma abordagem de aprendizado de mÃaquina. LTC, 2011.

Haralick, R. M.; Shanmugam, K.; Dinstein, I. H. Textural features for image classification. Systems, Man and Cybernetics, IEEE Transactions on, , n. 6, p. 610-621, 1973. 
Hotelling, H. Analysis of a complex of statistical variables into principal components. Journal of educational psychology, v. 24, n. 6, p. 417, 1933.

Joia, P.; Paulovich, F.; Coimbra, D.; Cuminato, J.; Nonato, L. Local affine multidimensional projection. Visualization and Computer Graphics, IEEE Transactions on, v. 17, n. 12, p. 2563-2571, 2011.

Jolliffe, I. Principal component analysis. Wiley Online Library, 2002.

Kamra, A.; Terzi, E.; Bertino, E. Detecting anomalous access patterns in relational databases. The VLDB Journal, v. 17, n. 5, p. 1063-1077, 2008.

Disponível em http://dx.doi.org/10.1007/s00778-007-0051-4

Kataoka, T.; Kaneko, T.; Okamoto, H.; Hata, S. Crop growth estimation system using machine vision. In: Advanced Intelligent Mechatronics, 2003. AIM 2003. Proceedings. 2003 IEEE/ASME International Conference on, 2003, p. b1079-b1083 vol.2.

LevinA, E.; Bickel, P. J. Maximum likelihood estimation of intrinsic dimension. In: Advances in neural information processing systems, 2004, p. 777-784.

LU, H.; OOI, B.-C.; TAN, K.-L. Efficient image retrieval by color contents. v. 819, p. 95-108, 1994.

Disponível em http://dx.doi.org/10.1007/3-540-58183-9_43

Méndez, A.; GonzÁlez, Z.; Jimenez, S. A.; Pérez, W.; Bracero, K. VVI: Visible vegetation index. Available at http://phl.upr.edu/projects/ visible-vegetation-index-vvi, 2013.

Meyer, G. E.; Neto, J. C. Verification of color vegetation indices for automated crop imaging applications. Computers and Electronics in Agriculture, v. 63, n. 2, p. $282-293,2008$.

Disponível em http://www.sciencedirect.com/science/article/pii/ S0168169908001063

Moran, M.; InOue, Y.; Barnes, E. Opportunities and limitations for image-based remote sensing in precision crop management. Remote Sensing of Environment, v. 61, n. 3, p. $319-346,1997$.

Disponível em http://www.sciencedirect.com/science/article/pii/ S003442579700045X 
Murty, M. N.; Devi, V. S. Pattern recognition: An algorithmic approach. Springer Science \& Business Media, 2011.

Papa, J.; Falcão, A. X.; Suzuki, C. T. N. Supervised pattern classification based on optimum-path forest. Int. J. Imaging Systems and Technology, v. 19, n. 2, p. 120-131, 2009a.

PAPA, J. P.; FALCÃO, A. X.; SuzUki, C. T. N. LibOPF: a library for optimum-path forest (opf) classifiers. http://www.ic.unicamp.br/ afalcao/libopf/, 2009b.

Paulovich, F. V.; Minghim, R. Hipp: A novel hierarchical point placement strategy and its application to the exploration of document collections. Visualization and Computer Graphics, IEEE Transactions on, v. 14, n. 6, p. 1229-1236, 2008.

Paulovich, F. V.; Silva, C. T.; Nonato, L. G. Two-phase mapping for projecting massive data sets. Visualization and Computer Graphics, IEEE Transactions on, v. 16, n. 6, p. 1281-1290, 2010.

Pearson, K. On lines and planes of closest fit to systems of points in space. Philosophical Magazine, v. 2, n. 6, p. 559-572, 1901.

Pham, M.; Susomboon, R.; Disney, T.; Raicu, D.; Furst, J. A comparison of texture models for automatic liver segmentation. In: Medical Imaging, International Society for Optics and Photonics, 2007, p. 65124E-65124E.

Ponti, M. Segmentation of low-cost remote sensing images combining vegetation indices and mean shift. Geoscience and Remote Sensing Letters, IEEE, v. 10, n. 1, p. 67-70, 2013.

Ponti, M.; Nazaré, T.; Thumé, G. Image quantization as a dimensionality reduction procedure in color and texture feature extraction. Neurocomputing (to appear), 2015.

Prati, R.; Batista, G.; Silva, D. Class imbalance revisited: a new experimental setup to assess the performance of treatment methods. Knowledge and Information Systems, p. 1-24, 2014.

Disponível em http://dx.doi.org/10.1007/s10115-014-0794-3

Sánchez-Maroño, N.; Alonso-Betanzos, A.; Tombilla-Sanromán, M. Filter methods for feature selection-a comparative study. In: Intelligent Data Engineering and Automated Learning-IDEAL 2007, Springer, p. 178-187, 2007. 
Settles, B. Active learning literature survey. Computer Sciences Technical Report 1648, University of Wisconsin-Madison, 2009.

Stehling, R. O.; Nascimento, M. A.; Falcao, A. X. A compact and efficient image retrieval approach based on border/interior pixel classification. In: CIKM'02 11th ACM Int Conf Information Knowledge Management, 2002.

Swain, M.; Ballard, D. Color indexing. International Journal of Computer Vision, v. 7, n. 1, p. 11-32, 1991.

Disponível em http://dx.doi.org/10.1007/BF00130487

Tuia, D.; Volpi, M.; Copa, L.; Kanevski, M.; Munoz-Mari, J. A survey of active learning algorithms for supervised remote sensing image classification. Selected Topics in Signal Processing, IEEE Journal of, v. 5, n. 3, p. 606-617, 2011.

VAPNIK, V. N. The nature of statistical learning theory. New York, NY, USA: Springer-Verlag New York, Inc., 1995.

VApnik, V. N.; Chervonenkis, A. Y. On the uniform convergence of relative frequencies of events to their probabilities. Theory of Probability and its Applications, v. 16, n. 2, p. 264-280, 1971.

Velez, D. R.; White, B. C.; Motsinger, A. A.; Bush, W. S.; Ritchie, M. D.; Williams, S. M.; Moore, J. H. A balanced accuracy function for epistasis modeling in imbalanced datasets using multifactor dimensionality reduction. Genetic Epidemiology, v. 31, n. 4, p. 306-315, 2007.

Disponível em http://dx.doi.org/10.1002/gepi.20211

Verhoeven, G. J.; Loenders, J.; Vermeulen, F.; Docter, R. Helikite aerial photography-a versatile means of unmanned, radio controlled, low-altitude aerial archaeology. Archaeological Prospection, v. 16, n. 2, p. 125-138, 2009.

WAN, L.; TANG, K.; Li, M.; Zhong, Y.; QIn, A. Collaborative active and semisupervised learning for hyperspectral remote sensing image classification. Geoscience and Remote Sensing, IEEE Transactions on, v. 53, n. 5, p. 2384-2396, 2015.

WANG, M.; HuA, X.-S. Active learning in multimedia annotation and retrieval: a survey. ACM Trans. Intell. Syst. Tech., v. 2, n. 2, p. 10:1-10:21, 2011. 
Woebbecke, D.; Meyer, G.; Von Bargen, K.; Mortensen, D. Color indices for weed identification under various soil, residue, and lighting conditions. Transactions of the ASAE, v. 38, n. 1, p. 259-269, 1995.

Zhang, N.; WAng, M.; WANG, N. Precision agricultureâĂ ̌̌a worldwide overview. Computers and Electronics in Agriculture, v. 36, n. 2âĂŞ3, p. 113 - 132, 2002.

Disponível em http://www.sciencedirect.com/science/article/pii/ S0168169902000960

Zhang, W.; YAng, Q.; Geng, Y. A survey of anomaly detection methods in networks. In: Computer Network and Multimedia Technology, 2009. CNMT 2009. International Symposium on, 2009, p. 1-3.

Zhang, Y.; Meratnia, N.; Havinga, P. Outlier detection techniques for wireless sensor networks: A survey. Communications Surveys Tutorials, IEEE, v. 12, n. 2, p. $159-170,2010$. 